University of Louisville

ThinkIR: The University of Louisville's Institutional Repository

Electronic Theses and Dissertations

$12-2019$

\title{
Teacher perception of administrative support for the implementation of a teacher evaluation system.
}

\author{
Natalie Redman Brown \\ University of Louisville
}

Follow this and additional works at: https://ir.library.louisville.edu/etd

Part of the Educational Assessment, Evaluation, and Research Commons

\section{Recommended Citation}

Brown, Natalie Redman, "Teacher perception of administrative support for the implementation of a teacher evaluation system." (2019). Electronic Theses and Dissertations. Paper 3334.

https://doi.org/10.18297/etd/3334

This Doctoral Dissertation is brought to you for free and open access by ThinkIR: The University of Louisville's Institutional Repository. It has been accepted for inclusion in Electronic Theses and Dissertations by an authorized administrator of ThinkIR: The University of Louisville's Institutional Repository. This title appears here courtesy of the author, who has retained all other copyrights. For more information, please contact thinkir@louisville.edu. 


\title{
TEACHER PERCEPTION OF ADMINISTRATIVE SUPPORT FOR THE
}

\author{
IMPLEMENTATION OF A TEACHER EVALUATION SYSTEM
}

\author{
By \\ Natalie Redman Brown \\ B.S., Eastern Kentucky University, 1998 \\ M.A.T., Bellarmine University, 2001 \\ M.A., Bellarmine University, 2009 \\ A Dissertation \\ Submitted to the Faculty of the \\ College of Education and Human Development of the University of Louisville \\ In Partial Fulfillment of the Requirements \\ For the Degree of \\ Doctor of Education in Education Leadership and Organizational Development \\ Department of Education Educational Leadership, Evaluation, and Organizational \\ Development \\ University of Louisville \\ Louisville, Kentucky
}

December 2019 
Copyright 2019 by Natalie Redman Brown

All rights reserved 

TEACHER PERCEPTION OF ADMINISTRATIVE SUPPORT FOR THE

IMPLEMENTATION OF A TEACHER EVALUATION SYSTEM

By

Natalie Redman Brown

B.S, Eastern Kentucky University, 1998

M.A.T, Bellarmine University, 2001

M.A., Bellarmine University, 2009

A Dissertation Approved on

October 10, 2019

by the following Dissertation Committee:

Dissertation Director, Jason C. Immekus, Ph.D.

Harrie Buecker, Ph.D.

W. Kyle Ingle, Ph.D.

Marco Munoz, Ed.D.

Deborah Powers, Ed.D. 


\section{DEDICATION}

This dissertation is for Jack. I am forever grateful for you, my son. You continue to inspire me with your ambition and determination to overcome any obstacle in your path. This dissertation journey has been a significant part of our lives for a while and throughout the process, I've watched you grow into an inspiring young man. I am eternally proud to be your mother and only hope you know how much you motivate me to be a better human being every single day 


\section{ACKNOWLEDGEMENTS}

I want to thank my parents for providing a model of what hard work and determination looks like. Throughout my life, you guys have both been committed to achieving your goals and supporting us. The older I get, the more I appreciate the childhood you gave Chris and me. We are so fortunate to have you two for parents. Throughout every decision I've made in life, you both have been right there to celebrate my success as well as help me learn from my mistakes. The love and support from both of you is overwhelming and instrumental in my life.

I would also like to acknowledge my entire dissertation committee for their support throughout this process. Thank you, Dr. Immekus, for your continued support throughout this entire process. I appreciate your commitment to helping me complete this degree. Dr. Powers, I appreciate everything you've done for me over the years. I can always take comfort in the fact that you have my back. Your words of encouragement and your understanding will always mean so much to me. Dr. Munoz, thank you for making me feel like I can achieve anything. Your "can do" attitude is contagious and much appreciated. Dr. Ingle, I appreciate your no-nonsense feedback and brutal truths. I know I didn't say it, but you helped pushed me to complete this degree and I appreciate you. Dr. Buecker, thank you for being an advocate for me. You have all challenged me 
in different ways and helped me stay focused on completing the dissertation. I am grateful for your contribution to my education.

I also have to thank Kara and Amy for everything during our coursework. We had some great times together working on our various projects. You guys were important partners and I appreciate our time together. Aaron, your way of explaining statistics is unrivaled. I would not have made it without your candid and supportive feedback. Thank you for everything.

Most importantly, I have to thank Jack. Thank you for being the most important member of my team. You have pushed me to accomplish more than I thought possible. I hope you will always remember this adventure and know that you can accomplish anything if you work hard and stay focused. The sky is the limit for you.

Travis, thank you for pushing me to finish this degree and for making it possible for me to do so. I am humbled by your love and support for me. You are a phenomenal teammate and I love you and our life more than I could ever put into words. Life sure is crazy sometimes, but I wouldn't be the same person if it were any other way. 


\title{
ABSTRACT \\ TEACHER PERCEPTION OF ADMINISTRATIVE SUPPORT FOR THE IMPLEMENTATION OF A TEACHER EVALUATION SYSTEM
}

\author{
Natalie Redman Brown
}

October 10, 2019

This study seeks to examine how new and experienced teachers in one urban public school district in Kentucky perceive support from their school administrators under the Professional Growth and Effectiveness System (PGES). A factorial analysis of variance (ANOVA) was conducted to examine potential interaction between more than one variable (i.e., difference in teachers who have a favorable, unfavorable, or neutral perception of administrative support of PGES, as well as years of teacher experience). Teachers who had a more positive view of administrative support had a higher perception of PGES. Teachers who have a favorable perception of administrative support are likely to have a more favorable perception of PGES than experienced teachers. Of the factors considered to affect teachers' perceptions of PGES, the teachers' perception of administrative support had a main effect while years of experience and the interaction between administrative support and years of experience did not have an effect of teachers' perception of PGES. 


\section{TABLE OF CONTENTS}

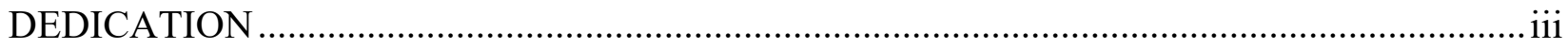

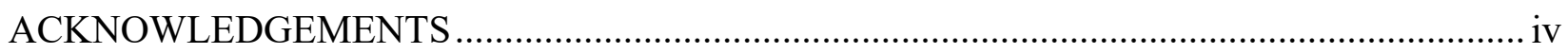

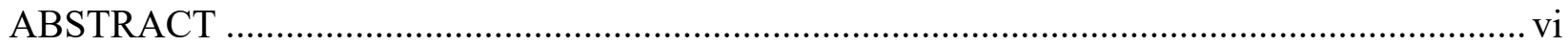

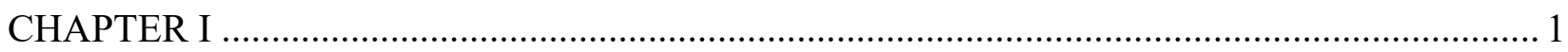

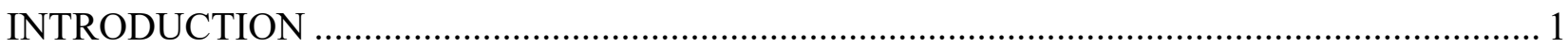

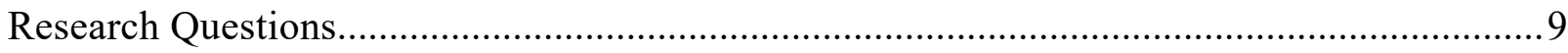

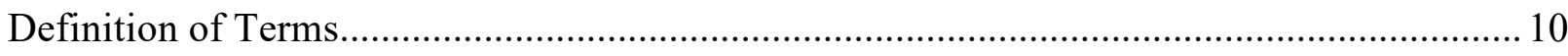

Research Design and Data Sources.................................................................................... 13

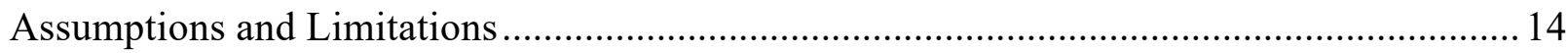

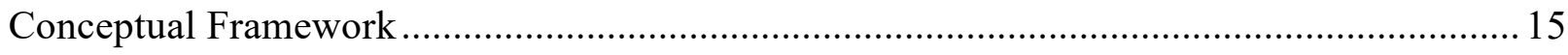

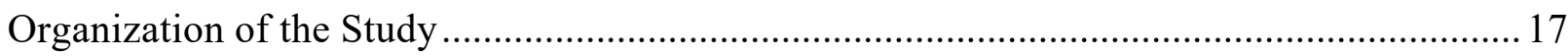

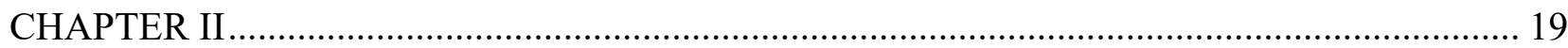

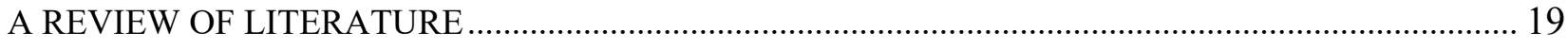

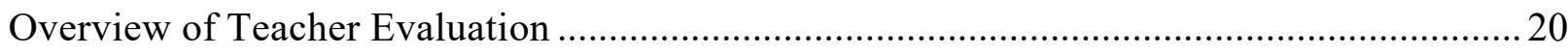

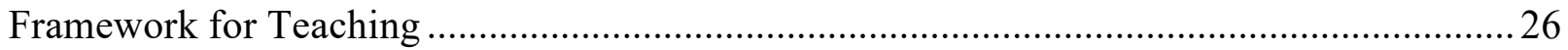

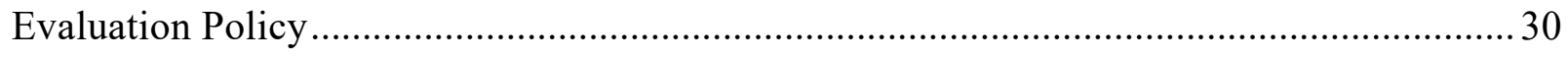

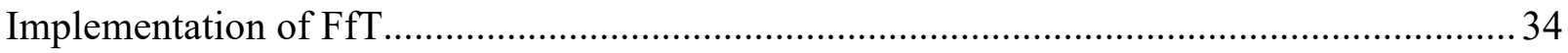

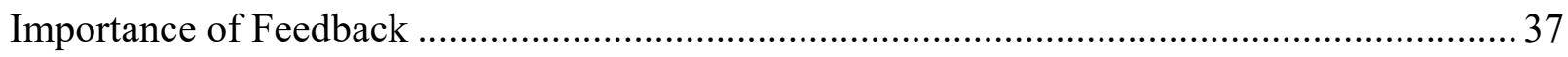

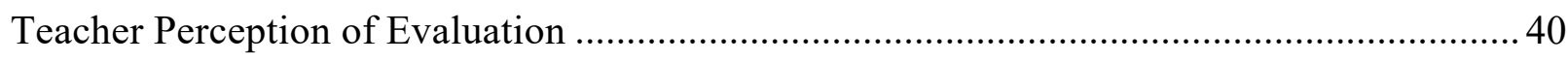

vii 
Gaps in Existing Literature

CHAPTER III

METHODOLOGY

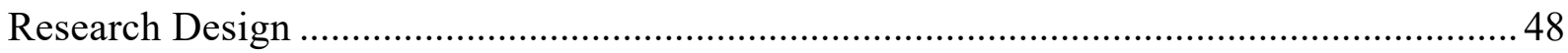

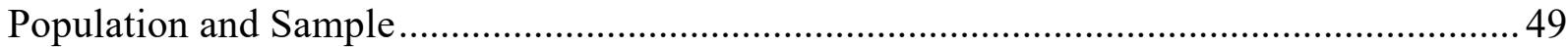

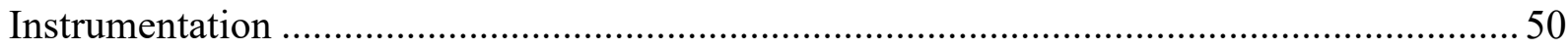

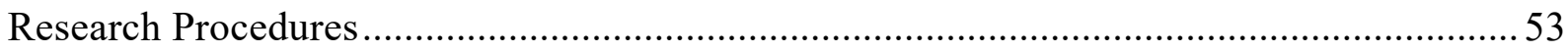

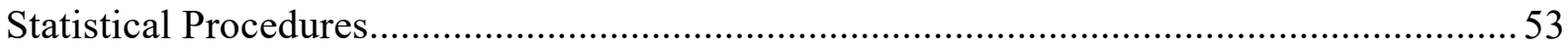

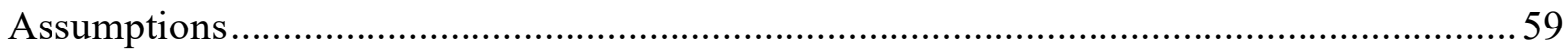

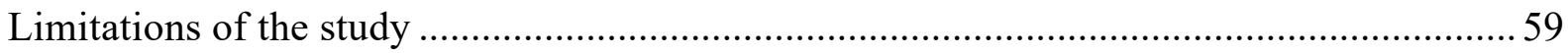

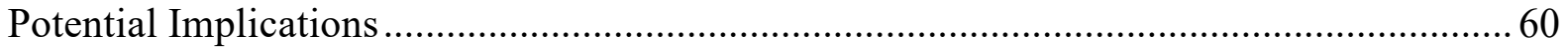

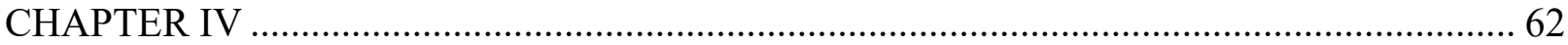

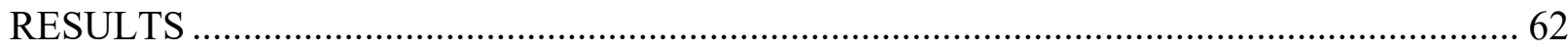

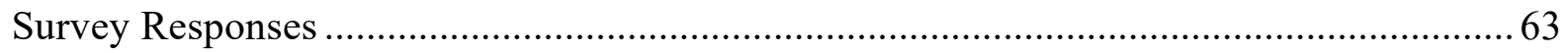

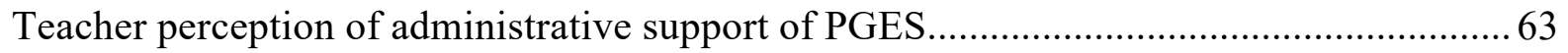

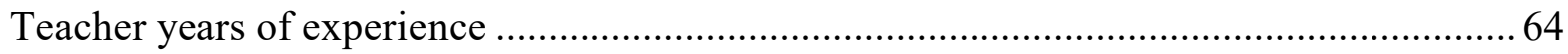

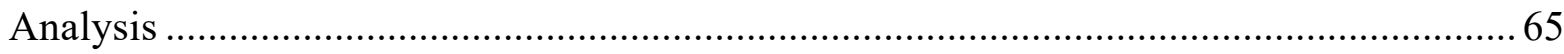

Research Question 1: What are teachers' perceptions of the Professional Growth and

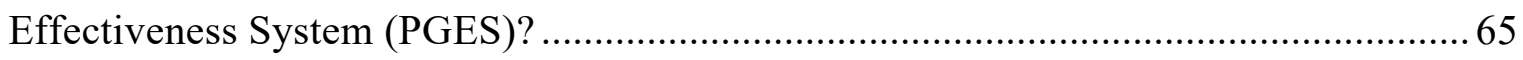

Research Question 2: Is there a statistically significant difference in teachers' perception of PGES between teachers with a favorable perception of administrator support of PGES, teachers with an unfavorable perception of administrator support of PGES, and teachers who are neutral in their perception of administrator support of PGES? 
Research Question 3: Is there a statistically significant difference in the perception of PGES between new and experienced teachers?

Research Question 4: Is there an interaction between teachers' perceptions toward administrative support and teachers' experience and teachers' perceptions of PGES? ..68

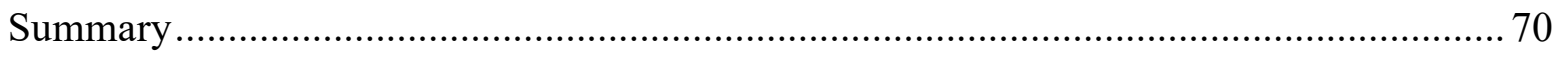

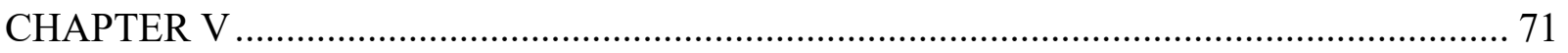

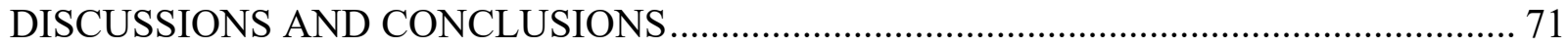

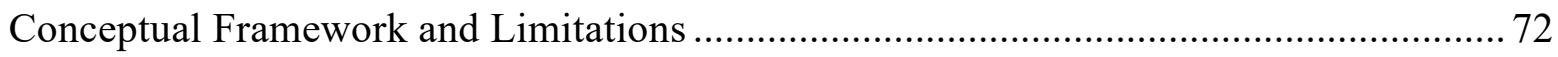

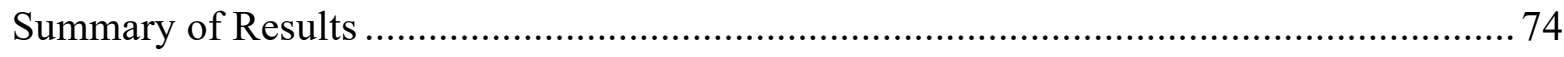

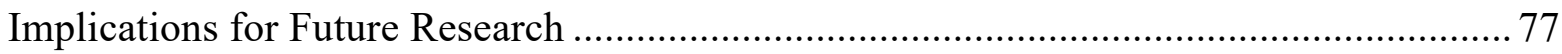

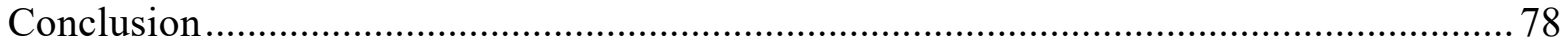

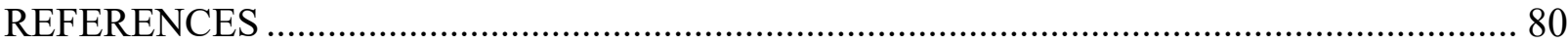

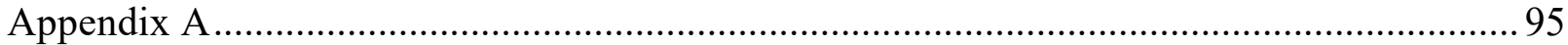

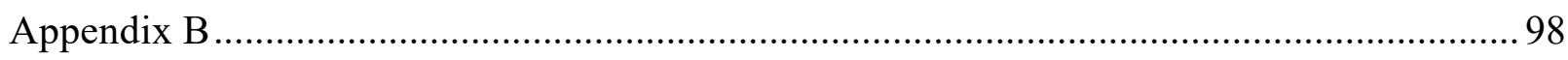

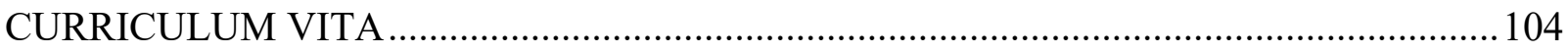




\section{LIST OF TABLES}

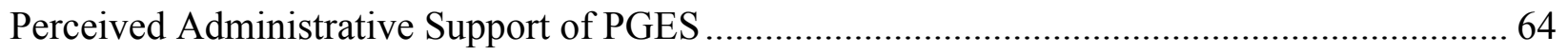

Means of Teachers' Perceptions of PGES between Administrative Support Groups ................. 66

Means of Teachers' Perceptions of PGES and Years of Experience....................................... 67 


\section{CHAPTER I}

\section{INTRODUCTION}

Increased accountability for student achievement in the United States has caused many states to reexamine their teacher evaluation systems (McGuinn, 2012). The use of teacher evaluation and its impact on student achievement has long been part of modern education reform (Mulford, 2003). Moreover, research on effective teacher evaluation indicates school leaders have the ability to improve a teacher's instruction and impact on student learning (Waters, Marzano \& McNulty, 2003). Policymakers expect principals and administrators to support teachers' effectiveness by providing quality feedback from evaluations as well as providing appropriate professional development opportunities to help support teachers. There is research to suggest frequent, accurate, and objective feedback on classroom observations can be a powerful resource for improving teaching (Jerald, 2012; Marshall, 2013; Taylor \& Tyler, 2011). The effective use of teacher evaluation and the need for improved teacher quality have been key focus areas of recent education reform efforts (Murphy, Hallinger, \& Heck, 2013). The purpose of this study is to explore both new and experienced teachers' perceptions of evaluation and administrator support.

Teacher evaluation has evolved over the past century. While evaluation once served a supervisory function, it now serves as one method to determine teacher effectiveness (Ellett \& Teddlie, 2003). Evaluations previously included managerial and 
behavioral components rather than instruction techniques (Ellett \& Teddlie, 2003). Because research suggests relationships between teacher behaviors and student achievement, the purpose of evaluation systems has changed to include a measure of teacher effectiveness (Darling-Hammond \& Ball, 1997). The desired outcome of teacher evaluation is to foster student growth.

Teacher evaluation has differed vastly across the country with local boards of education making determinations about what the components of evaluations include; the process differs greatly from state to state (Lindle, 2001) Sometimes, the evaluation included checklists or narratives written by the principal (Milanowski \& Heneman, 2001). Often, teachers were not evaluated yearly and the evaluation schedule was not always consistent (Boyd, 1989; Loup, Garland, Ellett, \& Rugutt, 1996). The lack of consistency in teacher evaluation components made comparing trends across districts and states difficult. The increased expectations for student achievement caused more states to consider adopting similar evaluation systems based on research (Danielson, 2008). In addition to varying processes and lack of consistency, the role of administrators has also changed from managerial to instructional. Previously, administrators served more as managers of the school than as instructional leaders. New evaluation systems challenge the idea of principal as building manager. Now there is a call for administrators to develop teaching quality among the staff (Murphy, Hallinger, \& Heck, 2013). The myriad of changes to teacher evaluation is a clear result of changing expectations of student achievement from the public.

The most recent iteration of teacher evaluation regulations is found in the Every 
Student Succeeds Act of 2015 (ESSA), and reauthorizes the Elementary and Secondary Education Act originally signed into law by President Lyndon Johnson. In 2015, President Barack Obama signed ESSA and the implications for teacher evaluation were immediately evident. A consideration for teacher evaluation under ESSA is the goal of increasing flexibility at the state level rather than federal mandates driving each decision about teacher evaluation (Department of Education, 2018). Modern evaluation reform efforts were originally sparked by President Obama's Race to the Top (RttT) initiative (National Council on Teacher Quality, 2012). Thirty-six states and the District of Columbia revised policies surrounding teacher evaluation in response to President Obama's challenge (National Council on Teacher Quality, 2012). In 2009, newly elected President Obama addressed concerns about education in America with the Race to the Top (RttT) initiative. The Rtt initiative challenged winners of the federal dollars to, among other reform efforts, revamp their teacher evaluation systems and include measures of student growth, a fair evaluation system for teachers, annual evaluations that include timely and constructive feedback, and use of the evaluation information to inform decisions pertaining to professional development, compensation, promotion, retention and tenure (U.S. Department of Education, 2011). As a result of the initiative, many states adopted a standards-based teacher evaluation (SBTE) system (Hallinger, Heck, \& Murphy, 2014). The SBTE systems include various types of observations, student achievement data, and student perception data. The purpose of SBTE systems is to measure and then support teachers as they develop instructional strategies that increase student learning (Danielson \& McGreal, 2000). The focus of this study is to explore new and experienced teachers' perceptions of evaluation and administrator support. Further, 
the district chosen for the current research continues to implement an SBTE system.

The RttT initiative motivated state departments of education to adopt new teacher evaluation systems and many adopted a standards-based teacher evaluation (SBTE) system approach to evaluation (U.S. Department of Education, 2011). With incentives from RttT, several states adopted new SBTE systems based on the work of Charlotte Danielson (Schachter, 2005). Danielson's Framework for Teaching (FfT) is a "researchbased set of components of instruction and grounded in a constructivist view of learning and teaching" (Schachter, 2005, p. 5). Before the adoption of the FfT, most states' evaluation systems were determined by local boards of education (Center for Public Education). The FfT has been formally adopted in eight states and has also been adopted in hundreds of school districts across the nation (Center for Public Education, 2019).

Each component of the FtF defines a distinct aspect of a domain with two to five elements describing a specific feature of a component (See Appendix A). Levels of teaching performance (rubrics) describe each component and provide a roadmap for improvement of teaching (Schachter, 2005). While FtF may be used for formative and summative observations, its full value is realized when it is used as a basis for professional conversations among practitioners as they seek to improve their teaching effectiveness (Schachter, 2005). The FtF may be used as the foundation of a school or district's mentoring, coaching, professional development, and teacher evaluation processes, thus linking all those activities together and helping teachers become more thoughtful practitioners (Schachter, 2005).

The Commonwealth of Kentucky adopted Danielson's Framework for Teaching 
(Kentucky Department of Education, 2019) as the Professional Growth and Effectiveness System (PGES). The purpose of PGES is to focus on specific teacher behavior and includes the domains and indicators found in the FfT (Kentucky Department of Education, 2019). The adoption of PGES was a result of the RttT initiative. Prior to PGES, teacher evaluation in Kentucky was an open-ended narrative administrators completed after a formal classroom observation. Teachers had the right to review and respond to the narrative, and the narrative was based on adopted standards for teachers, but the feedback was not tied directly to domains the way it is on the FfT (Lindle, 2001). Implementing a new teacher evaluation system became one of the key education initiatives in Kentucky (Ingle \& Wisman, 2018). Essentially, PGES provided a new tool for administrators to give teachers specific feedback with the goal of increasing teacher effectiveness. During the formal observation, the evaluator captures the conversation in the classroom with a focus on classroom environment and instruction (Danielson \& McGreal, 2000). McCaffrey et al. (2003) claim without some method of evaluating the effect of individual teachers, no particular person can be held accountable for educational outcomes. While McCaffrey et al. (2003) reported significant findings supporting revamped teacher evaluation systems, confusion about how to effectively measure a teacher's ability to influence student achievement was a difficult point of contention both in Kentucky and across the United States.

Principals and assistant principals have a responsibility to provide teachers with the support and feedback to improve their instruction under reforms such as No Child Left Behind Act of 20001 (NCLB) and RttT (DuFour \& Mattos, 2013), and, most recently, ESSA. Both NCLB and RttT required more accountability for student outcomes, 
with RttT including specific language about teacher evaluation (Klein, 2015). However, ESSA eliminated the requirement of attaching student outcomes to teacher evaluation. ESSA also allows states to make decisions about education policy decisions, including teacher evaluation systems. The selected district for the current research study chose to continue with the SBTE system for teacher evaluation. High school teachers in Jefferson County Public Schools (JCPS) were selected to complete the survey. Jefferson County is a large urban school district in Kentucky. Because the role of the school administrator has shifted from building manager to instructional leader, there is a need to understand how teachers perceive support from their principal and administrators. Historically, principals were tasked with more managerial roles (Finkel, 2012). The reform efforts demand increased instructional support from building administrators. Understanding teachers' perceptions of administrative support may shape teacher beliefs about the usefulness of teacher evaluation. Administrators will benefit from research on teacher perception of administrative support as well as teacher perception of PGES.

Major changes, including defining the characteristics of highly effective teachers, resulted from the increased accountability for student achievement and high-stakes test scores of students to evaluate teachers, at least in part, in some states (Marchant, David, Rodgers, \& German, 2015). Using high stakes testing as part of the teacher effectiveness measure has been a chief complaint from many educators (Marchant et al., 2015). The result of using high-stakes teacher evaluation to influence hiring and other high-stakes decisions call for a principal to be the instructional leader who can help teachers improve the quality of their instruction. With the shift in teacher evaluation to a SBTE approach, teachers and administrators had to revisit previous understandings of evaluation. The 
expectation that evaluation would measure teacher effectiveness was a shift from previous evaluation expectations that more narrowly focused on classroom management style (Schachter, 2005).

Little research has been conducted to determine the relationship between reform efforts and teachers' perceptions and instruction (Donaldson, 2012; Pizzi, 2009). With new evaluation systems being implemented across the country, it is important to understand teachers' perception of the evaluation system as well as their perceived level of support from administrators. Kilgore and Reynolds (2011) suggest that teachers must change their perceptions and actions in order to have successful change. Research that documents teacher perception of PGES is not prevalent, and includes studies by Shepard (2013), Murray (2014), and Towe (2012). The limited research on teacher perception of administrative support necessitates further investigation as districts continue to implement PGES and other SBTE systems of evaluation. Peterson (2000) found most teachers perceived evaluation as an exercise that did little to improve teachers' practice or instruction. Another concern is the wide interpretation of policy and the dramatic impact that perception of policy can change the outcome of new systems (Desimone, 2002; Spillane, Reiser, \& Reimer, 2002). For this reason, teachers' perceptions of their administrators and their support with the system are important to understand.

This study seeks to examine how new and experienced teachers in one urban public school district in Kentucky perceive support from their school administrators under the Professional Growth and Effectiveness System (PGES). Fully implemented in Kentucky during the 2015-2016 school year, PGES is still considered a newer approach to teacher evaluation for administrators and teachers. Administrative support in most 
schools included professional development sessions for teachers at the school and district level. For example, a review of several high school Comprehensive School Improvement Plans (CSIPs) are documents that detail the goals, objectives, strategies, activities, and resources a school needs each year (Kentucky Department of Education, 2019). The review of several CSIPs also revealed the inclusion of professional development sessions on PGES (Kentucky Department of Education, 2018). The present study seeks to inform educators on teachers' current perceptions of PGES as well as administrative support to improve the implementation process. As with any change initiative, there are implementation hurdles to overcome. Fullan (2001) concedes with any real effort to affect change, there will be an "implementation dip," a period of time where performance will actually decrease. It is during the implementation dip that leaders must be the most responsive. With the transition to PGES, educators across the nation have hit the implementation dip (Anderson, Butler, Palmiter \& Arcaira, 2016). Because current research on how evaluation impacts teachers' instructional practices is limited, this study will explore the current state of teachers' perception of PGES so administrators will be more responsive to teachers' needs moving forward as noted by Cantrell and Kane (2013).

Further, the present study will examine the perceptions of high school teachers on administrative support for PGES and how the PGES tool may improve instruction. Because teachers with varying years of experience may have differing needs and beliefs ((Anderson, Butler, Palmiter \& Arcaira, 2016), the study will categorize results by new and experienced teachers. The results of the study may guide administrators in providing appropriate professional development and other specific supports for teachers. The results 
of the study may also help determine if PGES is perceived to improve classroom instruction. Additionally, having access to research that may directly influence classroom practices will benefit educators. The information from the study seeks to provide useful information on planning future professional development and support for school districts. The findings will have implications for professional development, support at the school level, and the implementation of next steps with PGES. Furthermore, it will serve as a starting point to address concerns teachers with varying years of experience may have about the level of perceived support they receive from their school administrator. Figure 1 illustrates how the independent variables may interact with the dependent variable.

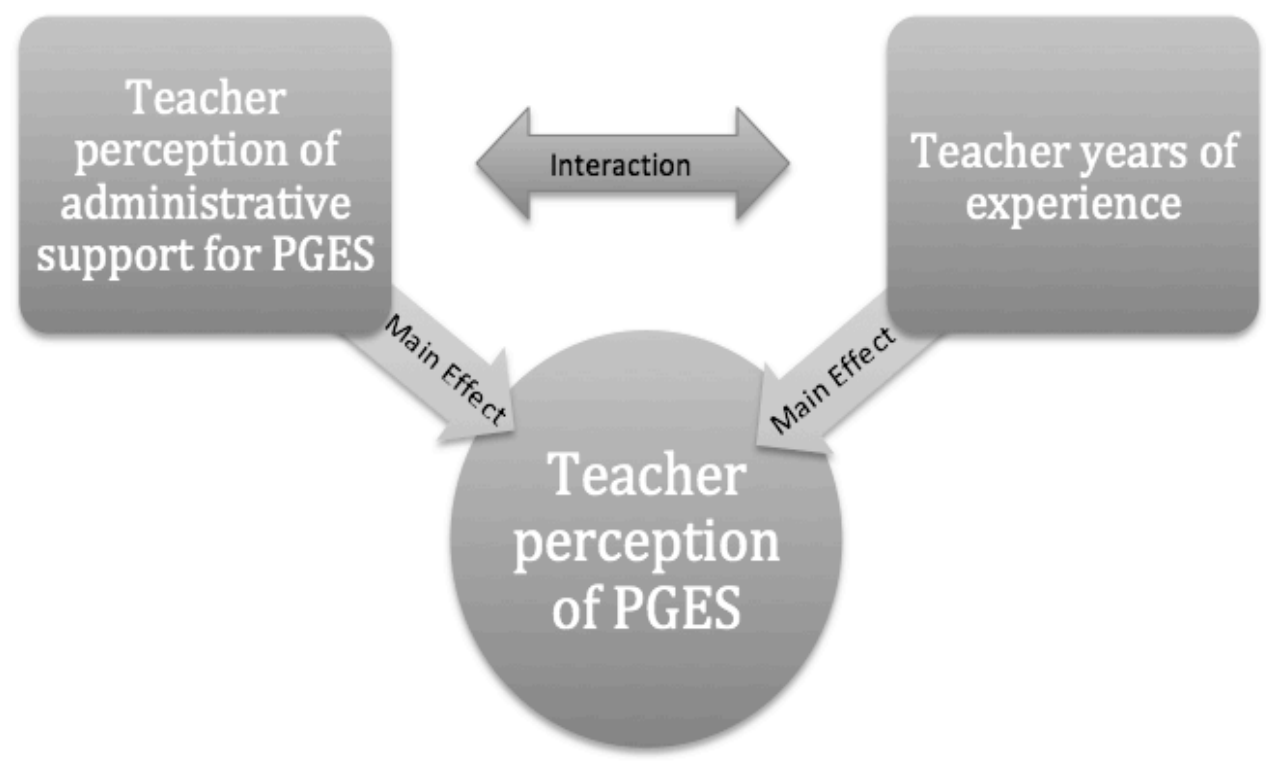

Figure 1. Factors and Outcome Variables for Teacher Perception of PGES

\section{Research Questions}

By investigating teacher perceptions of administrative support, this study will inform 
practitioners about the current perceptions of teachers in regards to the PGES, administrator support, and the perceived value the PGES tool has as a way to improve instruction. If teachers feel supported during the implementation of PGES, students may have access to higher quality instruction based on the feedback from the evaluating administrator. The results of the study will allow administrators to better plan professional growth opportunities for teachers to help both new and experienced teachers improve classroom instruction. The present study will address the following questions:

1. What are teachers' perceptions of the Professional Growth and Effectiveness System (PGES)?

2. Is there a statistically significant difference in teachers' perception of PGES between teachers with a favorable perception of administrator support of PGES, teachers with an unfavorable perception of administrator support of PGES, and teachers who are neutral in their perception of administrator support of PGES?

3. Is there a statistically significant difference in the perception of PGES between new and experienced teachers?

4. Is there an interaction between teachers' perceptions toward administrative support and experience and their perceptions of PGES?

\section{Definition of Terms}

For the purpose of the present study, the following terms are defined as follows:

Administrative support: The feedback, coaching, professional development or other support a teacher receives from a school administrator. 
Classroom observation: Refers to a formal or informal observation of teaching and learning as it occurs in a classroom or other learning environment (Shute, 2008).

Education reform: Refers to goal of changing education policy (Shute, 2008).

Effective teachers: Goe, Bell and Little's (2008) five-point definition of effective teachers will be used in this study; which includes a contribution to positive academic outcomes, the use of diverse resources to encourage learning opportunities, a focus on developing classrooms that value diversity and civic-mindedness, and collaboration with other professionals.

Evaluation system: The process of collecting data and making professional judgments about an educator's performance for the purpose of decision making.

Feedback: Refers to information communicated to the learner intended to modify his or her thinking or behavior to improve learning (Shute, 2008). According to Feeney (2007), the goal of the specific feedback is to improve the effectiveness of teaching and enhance professional growth.

Formative evaluation: A type of evaluation used to improve the professional skills of teachers (Danielson \& McGreal, 2000).

Framework for Teaching: "Research-based set of components of instruction, aligned to the INTASC standards, and grounded in a constructivist view of learning and teaching" (Danielson Group, 2013, para. 1).

Implementation: For the purpose of this study, implementation will refer to the execution of the plan and support of teachers with the new teacher evaluation system. 
Instructional strategies: Questioning and discussion techniques that cause students to think and reflect, to deepen their understanding and to compare their ideas to classmates (Danielson, 2011).

Perception: The way in which something is regarded, understood or interpreted (Oxford Dictionary, n.d., "Perception"). For the purpose of this study, perception will denote the respondents' understanding and assessment of the new teacher evaluation system and its likely impact on the respondent.

Professional Growth and Effectiveness System (PGES): Kentucky's adopted SBTE system to measure teacher effectiveness. PGES is adapted from Charlotte Danielson's Framework for Teaching.

Race to the Top (RttT): The 2009 initiative is a $\$ 4.35$ billion United States Department of Education competitive grant created to spur and reward innovation and reforms in state and local district K-12 education.

Standards Based Teacher Evaluation (SBTE): A method of teacher evaluation that uses multiple measures of teacher effectiveness including value added model, student voice, peer observation, and principal observation to determine teacher effectiveness (Danielson, 1996).

\section{Significance}

The significance of this study will include providing educational leaders a gauge to assess teachers' understanding of PGES as well as their perceived support from administrators, in terms of receiving effective feedback and coaching to improve instructional quality. Teacher evaluation systems across the nation are being redesigned. 
The most widely used model for current evaluation systems is the FfT (Danielson Group, 2013). Twenty states have implemented the FfT or an adaption of the FfT (Danielson Group, 2013). Kentucky uses the FfT but refers to the evaluation system as PGES.

Current literature indicates teacher evaluation is not being used to maximize instruction to support student learning (Brandt et al, 2007; Toch \& Rothman, 2008). As states have adopted standards-based evaluation systems (e.g., FfT), it is important to investigate how teachers' perceptions impact their instruction and their students' learning. Few studies have been conducted to explore the perceptions of teachers on the effectiveness of the new evaluation system and more information is needed to better understand how the system is shaping teaching behavior. Investigating teacher perceptions of PGES will allow the researcher to determine if conferences between administrators and teachers as a result of the PGES tool have an impact on instruction.

\section{Research Design and Data Sources}

The present study used a cross-sectional survey design to explore possible differences in teacher perceptions of administrative support between new and experienced teachers. An analysis of variance (ANOVA) model will be used in the present research to examine the difference between multiple groups (Field, 2014). Using the ANOVA model will help explain some of the variance and allow for a more accurate measure of the independent variable (Field, 2014). In order to provide a more accurate explanation of variance, the variable must be independent of the experimental effect (Field, 2014). Because the teacher evaluations required for PGES are evidence-based observations of teachers and students in the classroom, the researcher may not be able to assess the impact of other variables that may impact evaluations (e.g., previous 
achievement, socio-economic status, parental involvement). This is important because teacher evaluation has emerged as a key part of discussions in legislative sessions nationwide (Brandt et al., 2007; Toch \& Rothman, 2008). The unit of analysis in this study is teacher-level. Only schools designated as A1 schools will be included. In Kentucky, "A1" is defined as "a school under administrative control of a principal or head teacher and eligible to establish a school-based decision making council. An A1 school is not a program operated by, or as a part of, another school" (Kentucky Department of Education, 2018), meaning alternative or special schools will not be included in the research.

\section{Assumptions and Limitations}

To ensure that the results are free from unnecessary bias, it is important to prevent violations of the three main assumptions for linear models: normality, homoscedasticity of variance, and independence. Because ANOVA is a linear model, these assumptions were addressed. The normal distribution of data was addressed by including a representative sample of the population of teachers as well as the one sample Kolmogorov-Smirnov (KS) test (Field, 2014). The next assumption is homoscedasticy of variance and it was addressed by including populations with the same variance and Levine's test. Another consideration is independence of variables. The use of categories for both variables (years of experience and perception of PGES) ensured the independence assumption was met.

The survey questions took into consideration the other variables but isolated teacher perception. In addition, Scriven (1981) generated a list of accuracy problems with evaluation: change in the usual teaching practice caused by the observation visit, 
unreliable number of samples, personal biases of the evaluator, adult raters who do not think like students, style preferences of the evaluator, costs in time of lengthy classroom visits. These components are each contributing factors to evaluation results. However, the evidence-based format of PGES will calibrate results for teachers' evaluation results and mitigate potential evaluator bias.

\section{Conceptual Framework}

Ensuring students have access to a quality education is at the core of most educational reform initiative. Without understanding the relationship between PGES and student achievement, educators cannot make informed decisions that best support students. PGES, based on the Danielson (2007) FfT, is grounded in Shulman's (1987) research on pedagogical content knowledge and the Interstate New Teacher Assessment and Support Consortium (InTASC, 1992) standards. The InTASC developed a model of core teaching standards that illustrate what teachers should know and be able to do to help ensure students are prepared to enter college or the workforce (InTASC, 1992). Specifically, the standards detail what effective teaching and learning looks like in public schools. A goal of the standards is to empower students to take ownership of their own learning, to use their own experience to make sense of the content, and to have the capacity to adapt to a rapidly changing world (InTASC, 1992). These standards include common principles and foundations of teaching practice, and include all subject areas and grade levels necessary to improve student achievement (InTASC, 1992).

The FfT (2007) is divided into 22 components (and 76 smaller elements) clustered into four domains of teaching responsibility (Danielson, 2007). The domains include: 
planning and preparation, classroom environment, instruction, and professional responsibilities. The planning and preparation domain include a teacher's content knowledge and pedagogy. The classroom environment domain includes the classroom community and how a teacher fosters a supportive, learning-rich environment. The instructional domain is the actual teaching and monitoring student progress. Finally, the professional responsibilities domain includes communication to parents and community as well as reflecting on teaching and maintaining accurate records (Danielson, 2007). A teacher's rating ranges from ineffective, developing, effective, and highly effective and is based on a rubric with evidence-based indicators (Danielson, 2007). The FfT rates teachers on a scale of $1-4$ and includes the following terms: ineffective, developing, accomplished, and exemplary. The FfT is less subjective than previous evaluation models. The rating scale is considered less subjective because the evaluator scripts actual quotes from the teacher and students. The inclusion of actual quotes observed during the evaluation ensures the evaluator is not using subjective statements to describe the teacher's performance. The actual quotes are compared to a rubric and receive a score. This process allows more consistency in evaluation scores and feedback.

The FfT (2007) is based on constructivist theory and is intended as a formative instrument to help teachers improve their practice and is relevant to this research because the FfT is a central component of PGES. Because administrators' roles have transitioned to instructional leader, the FfT is a useful tool to help provide specific feedback to help develop teacher capacity. The theoretical foundation of Vygotsky's (1978) social constructivism and zone of proximal development along with theories of Piaget (1952) provide the conceptual framework in which learners are viewed as active participants. A 
fundamental aspect of Vygotsky's theory is the Zone of Proximal Development, a range of tasks that are too difficult for an individual to master alone, but can be mastered with the guidance of more-skilled peers (Vygotsky, 1962). In a constructivist classroom, the effective teacher creates a learning environment where engaged students interact, reflect, and construct deep understandings of important concepts (Brooks \& Brooks, 1999). The FfT provides a structured framework to help teachers create and support a studentcentered classroom.

Administrators with a clear understanding of the FfT can support teachers as they create the student-centered classroom, making teachers' perceptions of administrator support quite relevant in today's schools. If teachers have a more favorable view of their administrators and their ability to give viable feedback, students may have access to higher quality instruction. This study will guide administrators as they create systems of support in their schools. Additionally, understanding teachers' perceptions about the FfT will help determine what adjustments the current evaluation system needs to better support teachers.

\section{Organization of the Study}

Chapter I includes the following: the introduction, a rationale for the study, the purpose of the study, the research questions, the hypothesis, the assumptions and limitations, and definitions of key terms. In Chapter II, there is a detailed review of the literature surrounding the research of teacher evaluation as well as a review of how education policy has transformed teacher evaluation over the years. Chapter III provides context for the study, as well as the methodological procedures to address the research questions. Also, Chapter IV includes a discussion of assumptions and limitations of the 
study and Chapter V details the implications for future studies and policies. 


\section{CHAPTER II}

\section{A REVIEW OF LITERATURE}

The purpose of this study is to explore the implementation of the Professional Effectiveness and Growth System (PGES) and high school teachers' perception of administrative support with the new system. Further, the study will examine teachers' perceptions of PGES as an instructional tool to improve classroom instruction. This chapter will review the literature pertinent to the study. First, the review will provide an overview of teacher evaluation. Second, the discussion will detail Danielson's (2007) FfT. Third, the policy will be examined carefully. Fourth, the implementation of the Framework will be addressed. Fifth, the importance of feedback on evaluations will be discussed. Finally, there will be a discussion of the gaps in existing literature. The chapter concludes with the purpose of the present study, investigating teachers' perceptions of PGES and the level of perceived support from administrators to teachers to answer the following research questions:

1. What are teachers' perceptions of the Professional Growth and Effectiveness System (PGES)?

2. Is there a statistically significant difference in teachers' perception of PGES between teachers with a favorable perception of administrator support of PGES, teachers with an unfavorable perception of administrator support of PGES, and teachers who are neutral in their perception of administrator 
support of PGES?

3. Is there a statistically significant difference in the perception of PGES between new and experienced teachers?

4. Is there an interaction between teachers' perceptions toward administrative support and experience and their perceptions of PGES?

\section{Overview of Teacher Evaluation}

Until the 1970s, principals were mainly considered to be administrators whose primary role was maintaining an orderly environment (Valentine \& Prater, 2011). For example, teachers relied on the school administrator to manage behavior issues. Also, administrators were tasked with the daily operation of the school building and transportation of students. The impact of the administrator on student achievement was most closely associated with smooth operation of daily school procedures. When the role of the principal began to change in the early part of the 20th century, teacher evaluation was finally included in the job responsibilities (Bogart, 2013). However, the methods of teacher evaluation have remained essentially unchanged since the principal became responsible for most of the evaluation process (Attinello et al., 2006). With PGES in place, a dramatic shift in evaluation is clear. The days of lengthy and subjective narratives written by the administrator/evaluator have been replaced with evidence-based ratings that correspond to a rubric. This standards-based approach to evaluation marks a shift to the role of administrator to instructional leader.

Historically, teacher evaluation has not provided a clear connection between teacher behavior and student achievement (Marzano, Frontier, \& Livingston, 2011). It 
was not until the end of the nineteenth century and beginning of twentieth century that teacher evaluation began to evolve. Two prominent voices during this time were John Dewey and Frederick Taylor (Marzano et al., 2011). Dewey believed students should have ample opportunities to practice democracy, including an emphasis on studentcentered activities and differentiated instruction (Marzano et al., 2011). Taylor, however, believed that careful measurement of every activity would produce a sound method for teaching and that schools could be run similarly to factories (Marzano et al., 2011). Both men contributed to the changing beliefs about teacher evaluation: Taylor contributed a more systemic approach to education and Dewey contributed the notion of developing citizens (Bamburg \& Andres, 1991). Each contribution is relevant to evaluation today. Danielson's Fft, the core document for PGES, emphasizes a student-centered classroom. Taylor's systemic approach to education is evident in the evidence-based observations based on criteria from a rubric.

Teacher evaluations in the 1920 s focused on personal traits of the teacher and were directed from an ethical perspective (Daley \& Kim, 2010). Even with the changing beliefs about teachers, supervisors during this period were tasked with significant responsibilities that prevented providing teachers with adequate feedback to improve instruction (Ellett \& Teddlie, 2003). Teachers were viewed as servants in the community and their moral composition was an integral part of how a teacher was evaluated (Marzano et al., 2011). The impact of a teacher's effectiveness on student achievement was not considered in evaluations at this time. Teacher morality was deemed more important than instructional effectiveness. 
By the 1950s, the clinical approach was emerging as best practice for teacher evaluation. The process involved a "purposeful, symbiotic relationship between practitioner and resident, where observation and discussion drove both parties to higher levels of growth and effectiveness" (Goldhammer, 1969, p. 54). Since the 1950s, the focus of teacher observations has shifted to observable behaviors. This change reflected a greater reliance on objective measures of research focused on the learning process and helped steer educators toward more specific evaluation processes (Daley \& Kim, 2010). The beginning of teacher effectiveness research in the 1960s and 1970s led to the current beliefs about teacher effectiveness and evaluation. A more practical approach to capture activity in the classroom was the goal of teacher evaluations (Danielson \& McGreal, 2000). This teacher effectiveness research led to the current beliefs about teacher effectiveness and evaluation. There was a shift to include student outcomes as part of the teacher evaluation. Even with the shift to focusing on student outcomes, there has been "relatively little attention" given the potential long-term effects of teacher performance evaluations (Taylor \& Tyler, 2012). This study aims to address how teachers perceive evaluation from administrators.

Likely the most dramatic shift in education policy on teacher evaluation happened with the publication of $A$ Nation at Risk in 1983. The National Commission of Excellence in Education (1983) suggested that teachers were not adequately preparing students for life after school. Further, the report noted salary, promotion, tenure, and retention decisions should be connected to an effective evaluation system, and should include peer review so that teachers were compared against each other (National Commission of Excellence in Education, 1983). This caused educational reform in 
schools to focus on two main areas: length of the school year and more academic course work. In the 1990s, the next phase of teacher evaluation began and included high stakes assessment and the use of academic standards on which students were to be assessed as part of teacher evaluation (National Commission on Teaching and America's Future, 1996). The publication of What Matters Most: Teaching for America's Future argued in favor of connecting student growth to teacher evaluation (National Commission on Teaching and America's Future, 1996). This publication focused on teacher quality, which helped spur a renewed focus on teacher evaluation. The findings of the report were surface level. Nonetheless, the implications of the report are vast. Specifically, the role of the federal government expanded as a result of $A$ Nation at Risk. It also marks the period in educational history when instructional leadership models emerged (Hallinger, Heck \& Murphy, 2003).

Teacher evaluation continued to evolve with each reauthorization of the Elementary and Secondary Education. The legislation led to several changes in accountability in education. Changes in No Child Left Behind (2001) included the certification of teachers meeting federal requirements and schools meeting goals of student proficiency, called Annual Yearly Progress (AYP). Ensuring teacher quality was a primary focus of the reauthorized law. Highly qualified teachers were defined based on their level of academic attainment (Weems \& Rogers, 2010). Schools were also required to meet adequate yearly progress (AYP) targets based on student achievement. This achievement was determined by the rate of proficient test scores from students overall as well as in subcategories. The reauthorization also included expanded oversight for states and local district from the federal level. All of these changes created a need to ensure 
quality teacher performance in the classroom. Today's educational reform movement has shifted to effectiveness as defined by how well teachers perform with their students instead of assessing their knowledge of content (Stumbo \& McWalters, 2011). Therefore, teacher evaluation systems needed to be adapted so as to measure a teacher's impact of student learning.

President Obama's RttT initiative increased the accountability for teachers even more than NCLB. In 2009, RttT challenged states to revise teacher evaluation systems and offered significant financial incentives to do so. Thirty-one states enacted teacher evaluation reforms (McGuinn, 2012). Many of those states adopted SBTE systems that use evidence-based data collection from observations. The FfT is an example of a widely used SBTE system (Murphy, Hallinger, \& Heck, 2013). For example, Kentucky adopted PGES, which is based explicitly on the FtF in response to federal dollars from the RttT initiative. The extensive time and resources exhausted in the adoption of PGES make it necessary for educators to understand the new evaluation system to better support teachers and their needs during the transition.

Another result for the RttT initiative is the concept of quantifying target teacher behaviors, which may have a positive impact on student achievement because it can allow for more objective and specific feedback to teachers. A study of thirty-one teachers with consistent results producing student gains on state accountability tests was conducted to determine which teacher behaviors had a positive impact on student learning (Brophy \& Evertson, 1973). In their quantitative study, Brophy and Evertson (1973) selected thirty-one teachers to participate in the study because of their consistent student learning gains on state assessments. Data was collected from the observational 
study and correlations were presented in the findings. Brophy and Evertson (1973) found correlations between behaviors such as asking higher level questions, calling on random students, avoiding absences, creating a positive climate, and providing specific feedback to students and student achievement gains of accountability testing (Brophy \& Evertson, 1973). Further, Hattie (2009) conceded if teaching and learning are visible (i.e., if teacher behaviors are clearly connected to student learning objectives), student achievement increases.

Similarly, Taylor and Tyler (2012) conducted a study how evaluation affects teacher performance. The purpose of the study was to provide evidence that evaluation can "shift the teacher effectiveness distribution by improving teacher skill, effort, or both that persist long-run" (Taylor \& Tyler, 2012). The study included math teachers with five or more years in Cincinnati Public Schools who were scheduled for an evaluation, based on their contract. The experimental design was observational and extended over the course of one year. The findings indicate teachers are more productive during the school year when they are formally evaluated, and even more productive after the evaluation year (Taylor \& Tyler, 2012). For example, if a student has a teacher who has recently been through the evaluative process in Cincinnati, the student will typically score about 10 percent of a standard deviation higher in math than a similar student taught by the same teacher before the teacher was evaluated (Taylor \& Tyler, 2012). This study indicates evaluation can be valuable to improve teacher effectiveness because teachers are more intentional in their planning and delivery of instruction during years when they are evaluated. 
Throughout the past two centuries, teacher evaluation evolved in many ways. The role of the evaluator has shifted from simply supervisory to instructional coach. To date, the research is unclear as to how much impact evaluation has on teacher effectiveness, therefore this study is necessary to better understand the relationship between the new evaluation system and teachers. However, researchers agree teacher effectiveness is an important component of student achievement. From A Nation at Risk (1983) to the passage of No Child Left Behind (2001), educators continue to grapple with teacher evaluation as a tool to help improve teacher instruction. This study will not only measure teachers' perceptions of PGES, but it will also measure teachers' perception of administrator support with PGES. Exploring a possible relationship between teachers’ perceptions of both PGES and the support they believe they receive from administrators will give administrators insight in how to plan next steps to support teachers.

\section{Framework for Teaching}

Danielson's (2007) FfT is the most widely used framework for teacher evaluation in the United States (Danielson Group, 2016). The FfT is a standards-based teacher evaluation system using multiple, authentic sources of teaching evidence (Danielson, 1996; Danielson \& McGreal, 2000). The FfT is the 'go to' set of teaching standards for districts, regional cooperatives and states that seek to operationalize their standards for teacher evaluation (Danielson Group, 2016). The FfT was developed in 2009 in Charlotte Danielson's Measures of Effective Teaching (MET) project (Danielson Group, 2016). The MET project was comprised of 3000 teachers and the goal was to identify specific teacher behaviors that impact student learning (Danielson Group, 2016). It was designed 
to be used with teachers across the continuum of experience, from new to experienced, using multiple sources of evidence and very specific assessment rubrics to measure effectiveness (Danielson, 2007; Kimball et al., 2004; Song, 2006). The FfT is designed to assess teaching practice using standards and rubrics intended to improve teacher instruction and strengthen educational accountability (Borman \& Kimball, 2005).

The Danielson (2007) framework is based on the Praxis III criteria, which was developed by the Educational Testing Service. The knowledge base for the assessment criteria used in Praxis III is grounded in Shulman's (1987) research on pedagogical content knowledge and the Interstate New Teacher Assessment and Support Consortium (INTASC, 1992) standards. Shulman (1987) writes that teaching should emphasize comprehension, reasoning, transformation, and reflection. The Praxis III assessment criteria, which are similar to the conceptions of teacher responsibilities defined by Scriven (1994), comprise four categories: organizing content knowledge for student learning, creating an environment for student learning, teaching for student learning, and teacher professionalism. Organizing content knowledge for student learning refers to pedagogy and lesson planning. The domain is characterized by the teacher's understanding of the learning process as it applies to the content, the activities used to foster student learning, and knowledge of prerequisite student skills to master the content. Creating an environment for student learning includes creating a positive classroom culture that is respectful, as well as managing classroom behavior and space. This domain is observed during the formal observation. The other domain observed during the formal observation is teaching for student learning. This domain is characterized by communication strategies with students, questioning strategies, student engagement and 
assessment, and demonstrating flexibility and responsiveness. The fourth domain includes professional responsibilities and includes teacher reflection, communication with families, growing professionally, and demonstrating professionalism (Danielson, 2009).

Unlike the Praxis III, which is designed to be a "system of assessment, feedback and support for beginning teachers" (Danielson \& Dwyer, 1995), the Danielson framework is intended for all teachers to be a tool for professional growth. The components, elements and descriptors of the framework provide a common language for professional conversation. Earlier frameworks (Bloom, 1971; Hunter, 1982) established a "common language and permitted educators to conceptualize and discuss specific teaching practices" (Marzano et al., 2011). By using keywords, teachers can differentiate instruction based on cognitive levels. Further, Madeline Hunter's (1982) framework for direct instruction allows teachers to identify seven key components when planning a lesson including the anticipatory set, objective, instructional input, modeling, checking for understanding, guided practice and independent practice" (Marzano, et al., 2011). The influence of Madeline Hunter's framework shaped evaluation systems until the FfT was crafted (Marzano, et al., 2011). Adopted in 36 states, the FfT has become the most widely accepted definition of teaching (Danielson Group, 2013) making it an integral part of current education.

In order to gather more information about the usefulness of the FfT examining the relationship between the FfT scores and student achievement scores, a study was conducted to determine if standards-based teacher evaluation scores might be useful in 
research on teacher effectiveness (Milanowski, Kimball, and White, 2004). The study used multi-level statistical modeling to study the relationship between evaluation scores and state test results. Key findings include some evidence of a positive association between teacher performance as measured by the evaluation system and student achievement (Milanowski, Kimball, \& White, 2004). The researchers also note SBTE systems, such as the FfT, constitute an attempt to improve teacher effectiveness and teacher skills. The results of the quantitative study suggest SBTE systems can have a substantial relationship with measures of the student achievement (Milanowski, Kimball, \& White, 2004). The analyses were based on the value-added paradigm using student's prior year test score and other factors not in the teacher's control (e.g., ethnicity, English proficiency). There was a positive association with a more highly rated teacher evaluation and student achievement (Milanowski, Kimball, \& White, 2004). The implications are significant for this study. Teacher perceptions of support with PGES are a component of successful implementation and the results of this study indicate a need to educate teachers on the possible positive impact for student achievement using an SBTE system like PGES.

The Danielson Framework (2007) provides a concrete structure to align teachers' practice in order to provide more consistent feedback from administrators. The Framework provides a detailed map for novice-level practice through accomplished teaching (Danielson Group, 2013). There are four underlying assumptions in Danielson's Framework: students must develop deep conceptual understanding, developing high levels of understanding requires effective models of instruction, decisions made in the classroom are purposeful, and teaching is a profession (Danielson Group, 2016). The 
framework has "important uses in the service of teaching and learning and the uses demonstrate the framework's power to elevate professional conversations" (Danielson, 2007, p. 13). Danielson (2001) explains teacher evaluation systems need to include three major components: A clear definition of good teaching, a fair and reliable method to gather evidence of good teaching, and evaluators who make reliable and consistent judgments based on the evidence. Because the states that implemented a SBTE system are still in the first few years of full implementation, there is not much research on teachers' perceptions of the evaluation system. However, one study found a relationship between teacher effectiveness and student achievement as a result of SBTE systems like PGES (Milanowski, Kimball, \& White, 2004). There is a need for more research on SBTE systems as states have completed the first few years of implementation.

As evaluation systems are revamped and SBTE systems are used in many states, the FfT is more relevant today as a tool to help improve teacher effectiveness. The way a teacher understands the FfT and the perception of the FfT as a tool to improve instruction is helpful for administrators to understand as they plan various levels of support for teachers. Although in the early years of implementation, it is noteworthy to determine teachers' perception of the FfT so schools and districts can make informed decisions on the evaluation system.

\section{Evaluation Policy}

Policy surrounding teacher evaluation has changed significantly in recent years with reform efforts such as RttT and ESSA. To that point, the intended outcome of teacher evaluation has changed significantly from supervisory to a method to determine 
teacher effectiveness (Ellett \& Teddlie, 2003). With the shift to SBTEs, such as the FfT, education policies across the nation have been revamped. Improving instruction continues to be a foundational component in states' evaluation policies. Peterson (1995) concluded previous teacher reform efforts did not result in increased accountability or improved practice. Updating evaluation policies to include student achievement has long been a goal in the United States (Marzano, Frontier, \& Livingston, 2011).

One study that has implications for changing policy noted inflated evaluation scores for the majority of teachers. Weisburg, Sexton, Mulhern, and Keeling's (2009) study collected teacher evaluation data from twelve school districts in four states. With the goal of finding the connection between teacher evaluation and student achievement in mind, the researchers found alarming results of their study on teacher evaluation. The findings indicate nearly all teachers receive a high rating on evaluations despite have many students who significantly underperform (Weisburg et al., 2009). Further, the results of the mixed method study indicate evaluation of teachers is mostly compliancedriven and devalued in the education field (Weisburg et al., 2009). The findings of the report suggest the need for performance evaluation systems with clear and straightforward performance standards, frequent feedback to teachers, targeted professional development based on individual teacher needs, and distinct rating options The results of the study were parlayed into the RttT reform efforts and connected clearly to the work of Charlotte Danielson and the FfT (Weisburg et al., 2009). Limitations of the study include differing levels of implementations in the four states included in the study and the varying issues in school districts that are unique to that particular district. The results of the study are important because even though the school districts were 
comprised of widely varying types of schools, the results of the teacher evaluation were similar: most evaluations did not provide teachers with effective feedback and included ratings that were inflated. Similarly, this study will consider inflated or devalued evaluations in conjunction with teacher perceptions of support from their administrator.

With the requirements for teacher evaluations in the Race to the Top initiative, many states shifted their evaluation policies to include a standards-based teacher evaluation (SBTE) system to help teachers improve instruction. The goal of the new evaluation system is instructional improvement; however, the consensus of many researchers is teacher evaluation is a flawed system. Weisberg, Sexton, Mulhern and Keeling (2009) found shortcomings in the current teacher evaluation systems across the nation. They surveyed 15,000 teachers and 1,300 administrators in several states and found "infrequent and undifferentiated systems resulted in 99\% of all teachers earning a satisfactory rating" (Weisberg, Sexton, Mulhern and Keeling, 2009, p. 231). With student achievement scores declining in many areas, the satisfactory rating of almost all teachers raised red flags among educators. The researchers suggest teacher evaluation should be a process in which all teachers are evaluated annually, teacher evaluations should be based on clear standards and feature multiple measures of performance and should allow for multiple rating levels to describe differences in teacher effectiveness, and teacher evaluation should include frequent observations with constructive feedback (Weisberg, Sexton, Mulhern, \& Keeling, 2009). Disconnects between high evaluation scores and declining student scores highlights the importance of understanding teacher perceptions of the entire evaluation process. 
Weber (1987) asserted that teacher evaluation policies could help improve teacher instruction. He concluded there are four areas of concern to consider when making evaluation policy: coexistence of teacher development and accountability; supervision versus evaluation; utility of evaluation in improving teaching; and, the most productive, least time-wasting approaches to observation. Further, Darling-Hammond (2012) suggest similar policy recommendations for teacher evaluation systems. Darling-Hammond (2012) indicates seven criteria for an effective evaluation system: 1.) Teacher evaluation should be based on professional teaching standards, 2.) Evaluation should include multifaceted evidence of teacher practice, 3.) Evaluators should be knowledgeable about instruction and well trained on evaluation system, 4.) Evaluation should be paired with useful feedback and provide professional development opportunities, 5.) Evaluation system should promote teacher collaboration, 6.) Master teacher should be part of the review process, and 7.) There should be panels of expert teachers to help oversee the evaluation process. The panels include teacher leaders and administrators. Such panels can help the implementation process and help reduce the number of grievances (DarlingHammond, 2014). These criteria represent effective evaluation system and are noted in RttT (Center for Public Education, 2016). Further, the criteria are included in Kentucky's evaluation policy and are evident in the PGES tool used to measure teacher effectiveness.

Teacher evaluation policy has shifted over time in an attempt to align teacher quality with student achievement, and while the FfT includes the seven components, it is important to understand how teachers perceive the evaluation system and the level of support they receive from their evaluating administrator. The literature is not conclusive on how teachers' perceptions of FfT impact their classroom instruction. This study seeks 
to build upon the current literature and investigate how teachers' perceptions impact their ability to shape student learning.

\section{Implementation of FfT}

A key point to consider is the fidelity with which any program is implemented, and applies to teacher evaluation systems. Implementation research suggests the ways in which people make sense of and use such policies determines the nature of the changes that actually occur in schools (Spillane, Reiser, \& Reimer, 2002). Essentially, different school leaders may implement the two initiatives with varying levels of fidelity. This study seeks to examine the implementation of PGES from teachers' perspectives, which requires an examination of the Measures of Effective Teaching (MET) Project (2010).

Before it impacted the design and implementation of the FfT, the MET Project, launched in 2010, was a large-scale effort to study classroom observation instruments, student perception surveys, and student achievement gains (MET Project, 2010). The purpose of the study was to determine how to identify and promote good teaching (Cantrell \& Kane, 2013). Approximately 3,000 teachers volunteered to be part of the MET study (MET Project, 2010). The study incorporated multiple measures to observe teachers and make predictions about student achievement. With the understanding that a single measure would not be a reliable indicator of a teacher's effectiveness, the goal of the MET Project was to examine different measures of effectiveness. Each measure of effectiveness was configured with different weights of components to find the most stable combination of weights most accurately predicting teacher effectiveness. The weights included: achievement gains, student perception data, and observations (MET Project, 
2010). Data from the study included measures of student achievement from participating teachers' classrooms on standardized assessments, student surveys, recorded lessons, and teacher/administrator surveys (MET Project, 2010).

The goal of the MET study was not to find the most important weight, but to find the most effective combination of weights and examine the "differing trade offs" for the various models (MET Project, 2010). Ultimately, the MET Project (2010) served as a foundational component for other practitioners to develop evaluation systems to meet varying needs. The MET Project (2010) drew from previous studies on teacher evaluation. The findings of the study indicate a more balanced approach - which incorporates the student survey data and classroom observations - has two important advantages: ratings are less likely to fluctuate from year to year, and the combination is more likely to identify teachers with better outcomes on assessments other than the state tests (Cantrell \& Kane, 2013). The findings help inform states, such as Kentucky with PGES, as they implement new evaluation systems.

In a study to better understand teachers' perceptions on the evaluation system as it was initially implemented, Kimball (2001) noted the "nature of implementation can have an impact on how evaluation systems are perceived by teachers and administrators" ( $\mathrm{p}$. 207). Two large school districts were selected for the mixed-method study. The purpose of the study was to fully understand the practitioners' perspectives on the evaluation system in schools perceived to be successfully implementing the new system as well as schools perceived to be struggling with implementation of the new system (Kimball, 2001). Kimball interviewed teachers to understand their perceptions of how the new evaluation system was working and the participants' perceptions of the impact of the new 
system. Key findings from Kimball's study indicated most teachers and administrators agreed the evaluation enhanced evaluator feedback. Probationary teachers generally viewed the system as having an impact on their teaching practices. Kimball suggested future studies investigate how standards-based evaluation systems are impacting the evaluation process related to instructional change and student achievement. Along with the impact of the evaluation process and student achievement, it will be important to understand how teachers view the evaluation process and how well they are supported by administrators.

In a similar study, Sartain et al. (2001) conducted a study on teacher evaluation in the Chicago Public Schools. The study provided research-based evidence that a revised teacher evaluation system can improve instruction (Sartain et al., 2001). The purpose of the study was three-fold: improve teaching and learning in the school district, develop a stronger professional learning climate among teachers and principals, and foster a constructive climate around teacher evaluation (Sartain et al., 2011). A mixed-methods approach was used with collected data and interviews with teachers and principals. Over half of the principals expressed favorable comments about the new evaluation system (Sartain et al., 2011). Principals who did not favor the new system tended to say it was "too labor intensive given the numerous district initiatives being simultaneously implemented in their schools" (Sartain et al., 2001, p.2). The study found the new teacher evaluation system had potential to impact school-wide change. Sartain et al. (2001) noted future implications included the consideration of practical issues when discussion teacher evaluation systems (e.g., purpose of formal evaluation, logistics of the observations, required training for administrators and teachers, and evaluator accountability). While 
this study examined administrator perceptions, the findings indicate that perceptions of the evaluation system can shape the level of implementation. A study to examine teacher perception of PGES can provide similar insight and expand the current pool of knowledge surrounding evaluation systems.

In the first few years of implementation, Kentucky schools benefit from studies on the practical issues and perceptions of the PGES system so educators can consider what is working and what is not. It is important for educational leaders to be keenly aware of new research because it is still not completely clear whether or not PGES can measure teacher effectiveness. A clear understanding of the literature surrounding the implementation of PGES is important before beginning to investigate teachers' perceptions of PGES. Additionally, exploring any relationship between teachers' perceptions of PGES as well as teachers' beliefs about administrator support with PGES will provide insight on whether or not teachers' beliefs about PGES is related to how much support teachers perceive they get from their administrators.

\section{Importance of Feedback}

Providing adequate feedback to teachers is a vital component to help teachers improve. John Hattie's (2012) research illustrated the importance of specific feedback to students. Providing students with effective feedback causes significantly more learning for students. The same is true for teachers. When evaluators provide specific feedback to teachers, there appears to be more of an impact than when teachers do not receive any feedback (Jerald, 2012). Other researchers, Danielson and McGreal (2000) describe using feedback from evaluators in classroom observations to create a two-way dialogue in which that feedback can be discussed between the teacher and principal or administrator. 
Further, Danielson \& McGreal (2000) assert feedback should be based on descriptive and observable data. Both the notion of creating a two-way dialogue between teacher and principal and ensuring descriptive and observable data are emerging themes in the literature as possible catalysts to improve teacher performance (Danielson \& McGreal, 2000). The quality of feedback from administrators may influence teacher perception of the usefulness of evaluation as an instructional tool.

One study (Kimball, 2002) builds on this work about the importance of feedback. Kimball conducted a qualitative study to determine how evaluation systems based on the Framework for Teaching (Danielson, 2003) impacted the nature of evaluation feedback. Three school districts were included in the case study. The researcher used purposive sampling techniques to select the schools to participate in the study on teachers' perceptions of the evaluation feedback (Kimball, 2002). The teachers were interviewed using a semi-structured interview protocol. Kimball (2002) found teachers and administrators believed the new evaluation system was an improvement from the previous system, but the study was inconclusive on the credibility of the feedback. The results varied, in part, because evaluators' ratings differed based on motivation, skill, and context. For example, the results may be mixed because there could be a lack of alignment between what is taught and what is on the assessment. Also, there could be mixed results because the evaluating administrator used the observation tool as more of a morale building experience rather than a tool to improve instruction. The varied results of the study mark another reason it is important to explore teacher perceptions of the evaluation tool. Administrators need to have a grasp on what teachers believe to be true about the system in order to use the system as a tool to improve teacher instruction. 
Along with detailed feedback, regular feedback is associated with better perception of evaluation. Much of the research is in favor of bi-weekly observations with detailed feedback based on the rubric and included next steps to support teacher learning (Jerald, 2012). As evaluation systems are updated to include a more specific focus on teacher improvement in relation to student achievement, principals and teachers will need to learn how to have more meaningful conversations with specific feedback. Ultimately, providing teachers with detailed feedback may help them support students more effectively and improve student achievement (Danielson, 2001). Moreover, failure to provide accurate feedback can be detrimental in two ways. First, if weak teaching practices are mislabeled as strong or if adequate feedback is not provided, future student engagement could be impacted. If a teacher is not given proper feedback, weaker practices could become part of the teacher's skill set. Additionally, if a strong teaching practice is misclassified as weak, a teacher could make changes that would lessen the quality of the instruction.

Just as students need feedback from teachers to improve, teachers need feedback from evaluating administrators. Kentucky's PGES is a system designed to provide evidence-based feedback to teachers based on a rubric with specific criteria. Teachers' perception of level of specific feedback will guide administrators in determining next steps for the evaluation process. If the PGES evaluation is not valued by teachers, it may not be favorably viewed as a tool to improve instruction. Conversely, the PGES tool may be more favorably viewed because of the specific classroom evidence and the connection of the evidence to the rubric to determine an evaluation score. Either way, teacher perception drives the use of the tool as a method to improve instruction. 


\section{Teacher Perception of Evaluation}

Administrators have evaluated teachers for more than a century. During that time, the scope and purpose of evaluations has changed. Historically, evaluation has been designed around teacher behavior or performance (Danielson \& McGreal, 2001, Ellet \& Teddlie, 2003). The evaluations focused more on classroom rituals and routines and teacher personality; there was little or no emphasis on student outcomes (DarlingHammond et al., 1983). Often teachers perceived the evaluation process as an exercise that did little to improve teachers' practice or instruction (Peterson, 2013), yet, teachers often view the evaluation as a very personal critique of their ability and performance (Barnett, 2006).

Teacher perception of evaluation influences the extent to which evaluation shapes teacher behavior. Halverson, Kelley, \& Kimball (2004) conducted a case study research to determine how principals use evaluation to help teachers improve their practice, and the results indicated that the impact of the feedback. The study included interviews from fourteen schools in the western United States. Additionally, written teacher evaluations and demographic data were analyzed in the case study. The results indicated a wide discrepancy between teacher and principal perception on written evaluation feedback. Generally, teachers indicated principal's written evaluation feedback shaped instructional practices in the classroom. However, principals typically did not view the feedback as transformational for teachers. The varying perceptions of teacher evaluation data underscore a larger validity issue for using teacher evaluation to predict or assess student achievement. Administrators need to understand how teachers perceive the feedback they give to teachers. Administrator awareness of teacher perception will be addressed in this 
study as it may support professional development planning and increased teacher support. Key findings indicate both principals and teachers felt the FfT process allowed for more productive dialogue. Also, principal perception of the evaluation process ranged from a belief that the new system built morale in the school to the limiting time constraints making the evaluation system cumbersome and not helpful for helping develop teacher capacity.

More evidence of differing perceptions comes from Donaldson's (2012) study on perceptions of evaluation found both tenured and non-tenured teachers did not believe the feedback from their evaluations changed their pedagogy. However, the study indicated the evaluation system did affect how teachers planned their lessons (Donaldson, 2012). Another study on teacher and administrator perception of evaluation indicated a belief about the changing role of the principal (MetLife Survey of the American Teacher, 2013). Further, principals in the study indicated the job was much more challenging than it was five years ago (MetLife Survey of the American Teacher, 2013). The research suggests teachers' perception of evaluation does not cause them to plan differently or reconsider beliefs about teaching. Essentially, both teachers and administrators have made changes due to the evolving evaluation system but neither believes evaluation will reshape basic beliefs about teaching.

Doherty (2009) surveyed 170 teachers in a suburban school district in Massachusetts using the Teacher Evaluation Profile (TEP) and interviews from several small focus groups. The teachers surveyed believed that their current evaluation system could be improved by "differentiating the teacher evaluation system, reducing the amount 
of paperwork in the process, increasing the number of informal observations and walkthroughs, developing differentiated rubrics for different teaching positions, and using multiple sources of data" (p. 4). Teachers noted the current system of evaluation impacted their growth professionally, and the evaluations positively impacted school improvement.

Ultimately, teachers have their own opinions and beliefs about evaluation. It is relevant for administrators to understand what teachers believe to be true about evaluation in order to make better support decisions for teachers. If teachers regard administrative feedback as relevant to their classrooms and quality of instruction, they may perceive the evaluation as a useful tool to improve instruction. More research on teacher perception of evaluation is needed to better understand how evaluation can be used to improve instruction. This study seeks to explore teacher perceptions of evaluation in order to help administrators provide quality feedback to teachers.

\section{Gaps in Existing Literature}

Currently, there are few studies about teachers' perceptions of PGES and administrative support. While there has been extensive research on teacher evaluation, there is minimal research on teachers' perceptions of how PGES can be used as a tool to improve instruction. The literature on the new teacher evaluation system is still emerging and is far from complete. There are insufficient numbers of studies for educators to examine on the topic of the new evaluation system. The reliability and validity of the evaluations need to improve in order to have better understanding of how the new evaluation system may help improve teacher instruction (Darling-Hammond, 2012). 
Maintaining and cultivating support for the new system among teachers and administrators is another important component of measuring the effectiveness of the new system. As the new system is in place over time, it will become imperative to determine if it does in fact improve teacher effectiveness.

Measuring teacher effectiveness is a complex task that no singular evaluation measure can capture completely. As states adopt revised evaluation policies, there is great need to study the new evaluation systems. Current literature does not clearly connect the quality of feedback to changed instructional practices (Donaldson, 2012). A sense of mistrust is another factor that may have a negative effect on teacher growth. These shortcomings were the impetus for developing a new evaluation system so good teaching could be fleshed out and quantified. Specifically, the observation includes direct quotes from the teacher and students in the classroom. The quotes are compared to a standardsbased rubric to determine an evaluation score. This level of quantifying teacher evaluations is an example of the shift in teacher evaluation systems. The FfT allows teachers to improve performance by reflecting on feedback from administrators. Previous evaluation systems were more summative and did not provide a formative opportunity for administrators to coach and teachers to improve instruction (Sartain et al., 2011). Evaluator and teacher buy-in is necessary for the FfT system to be fully realized. Reflection from the feedback is a key difference in this system compared to previous ones (Donaldson, 2012). A mentality of continuous improvement is required in order for a formative evaluation system such as FfT to be useful. Additional research may be needed to determine the effectiveness of the quantified evaluation system. 
The results of this study will allow administrators to make determinations on how to support teachers in the new evaluation system. If there is a relationship between teachers with a favorable perception of PGES and a favorable perception of their administrator support, then administrators can make more informed decisions on professional development and teacher support. Currently, there is relatively little literature on how PGES measures effective teaching. Although the MET Project was the most extensive research conducted on effective teaching, the fidelity of implementation in Kentucky was not a factor. Therefore, researching teachers in Kentucky to determine their knowledge and perspective on PGES addresses a gap in the literature. This study will contribute to the knowledge by exploring the potential relationship between teachers with a favorable perception of PGES and a favorable perception of administrative support. This may provide meaningful next steps to administrators as they lead their schools. Specifically, if their teachers have a neutral or unfavorable perception of PGES and a neutral or unfavorable perception of administrative support then administrators can make changes to the school culture surrounding evaluation. By understanding teachers' comfort level and beliefs about PGES, administrators will be able to provide more responsive and helpful supports to teachers. This may include providing professional development for teachers, one-on-one coaching sessions for teachers, and conferences. The new teacher effectiveness system, PGES, needs to be understood as a complete departure from traditional teacher evaluation systems. The new system, PGES, requires direct quotes from both teachers and students and decreases the subjectivity of older evaluation models. Amrein and Berliner (2002) document the number of historical attempts to reform teacher evaluation. Previously, teacher evaluation varied greatly 
among districts and states and the process did not require matching teacher and student dialogue to a standards-based rubric. Moving forward, understanding teachers' perceptions of PGES will guide conversation and conferences and may even help determine the level of success with the implementation of PGES. The following chapter will discuss the methodology that will be used in the study to investigate the perceptions of teachers on PGES.

The new teacher evaluation system, PGES, is intended to measure effective teaching. Current literature on the new teacher evaluation system with respect to teaching effectiveness is neither comprehensive nor complete. The MET project (Cantrell \& Kane, 2013; Jerald, 2012; Kane \& Staiger, 2012) provided the most detailed analysis to date. The fidelity with which PGES is implemented may determine the success or failure of the new system. Current literature articulates measures of teacher effectiveness (Cantrell \& Kane, 2013; Gates Foundation, 2013; Jerald, 2012) but does not examine implementation and perception. Finally, cultivating administrator and teacher support is vital to the successful implementation of the new teacher evaluation process (Kimball, 2002; Sartain et al., 2011; White et al., 2012).

While there have been many studies on teacher evaluation, there is limited research on SBTE systems such as the Fft, known as PGES in Kentucky. More work is needed to determine how teachers perceive administrative support so school districts can better support teacher effectiveness. By determining teachers' beliefs about evaluation, it will be easier to develop more appropriate systems of support for teachers at all different experience levels. The implications of this study include helping school districts better 
support principals and teachers with the new evaluation system. Further, the study will contribute to the literature on teacher perceptions and allow for a more effective implementation process in schools. Exploring teachers' perceptions of the evaluation process that have varying amounts of experience will provide detailed next steps for administrators. 
CHAPTER III

\section{METHODOLOGY}

The purpose of the study was to examine teachers' perceptions of the PGES framework for teacher evaluation. Specifically, the study examined whether teachers with a positive perception of administrative support had a favorable perception of PGES and whether years of teacher experience is related to teachers' perception of PGES. Study findings are intended to inform administrators about teacher perceptions of administrator support with PGES. To answer the research questions, a cross-sectional survey design was used to explore these relationships; data were gathered from a representative sample at a specific point in time. Cross-sectional research involves using groups of people who differ in the variables of interest such as perceptions of PGES, perceptions of administrative support and years of teaching experience but share other characteristics such as the sample consisted of only teachers.

The research questions are as follows:

1. What are teachers' perceptions of the Professional Growth and Effectiveness System (PGES)?

2. Is there a statistically significant difference in teachers' perception of PGES between teachers with a favorable perception of administrator support of PGES, teachers with an unfavorable perception of administrator support of 
PGES, and teachers who are neutral in their perception of administrator support of PGES?

3. Is there a statistically significant difference in the perception of PGES between new and experienced teachers?

4. Is there an interaction between teachers' perceptions toward administrative support and experience and their perceptions of PGES?

Chapter III is organized into the following sections: Research Design, Instrumentation, Research Procedures, Statistical Procedures, Assumptions, Limitations of the Study, and Potential Implications.

\section{Research Design}

A cross-sectional research design was used to collect data from high school teachers in Jefferson County Public Schools (JCPS), a large urban school district in Kentucky. Cross-sectional survey designs are a form of research where the researcher observes what goes on without interfering by measuring several variables at a single point in time (Field, 2009). This type of research differs from experimental research because, unlike experimental research where one or more variable is manipulated to measure effect, cross-sectional research provides a design where the researcher can measure several variables at one point in time (Field, 2014). Using a cross-sectional survey is effective for providing a snapshot of the current behaviors, attitudes, and beliefs in a population and will be important for this research because PGES is a relatively new system for evaluating teachers (Gay, Mills, \& Airasian, 2009). A cross-sectional survey design was chosen for this study to examine the perceptions of both new and experienced 
teachers to measure their perceptions of PGES and administrative support because it is not realistic to manipulate the evaluation procedures for teachers. Survey protocols were used to collect survey-response data from teachers.

The survey instrument used for this study was adapted from Stiggins and Duke's (1988) Teacher Evaluation Profile (TEP). This particular research design allowed for a generalization of a sample population so inferences were made about the current perceptions of teachers (Creswell, 2014). Because perceptions and understandings are constantly changing, it is important to ascertain the most current data. The survey design allowed for a snapshot of high school teacher perceptions of PGES and was administered in August 2018.

\section{Population and Sample}

The target population for the cross-sectional survey were teachers at the 18 high schools in a large, urban school district in Kentucky. The 18 high schools selected serve students from grades nine through twelve. There are three additional high schools in the district that were not included in the study because the school population at those schools includes grades before the ninth grade. The focus of the present study was to explore grades nine through twelve, so the other three schools were omitted. The district selected for this study, JCPS, serves approximately 106,000 students (PK-12) and employed approximately 1,728 high school teachers (JCPS Databooks, 2017). This particular district was chosen because it is in one of the states that adopted a SBTE system (PGES) and will continue to use PGES after the adoption of ESSA. The 18 high schools that comprise the urban school district were selected because the district was among the top 
30 largest school districts in the United States serving approximately 106,000 students. In the selected district, there were a total of 6,121 teachers. Of the 6,121 teachers $84 \%$ were white, $13.3 \%$ African-American, .01\% Hispanic, and $0 \%$ were classified as two or more races.

In this study, a sample size of approximately 173 high school teachers from this district was sought. The total number of high school teachers in the district is 1,730 . Survey research ncludes a sample size based on a fraction of the population. The sample size for this research was approximately ten percent of the total number of high school teachers in the urban school district. Ten percent of the total population of high school teachers will provide a representative sample of the population, which determined the target number of teachers needed for this study (Creswell, 2014). The high school teachers who participated in this study were current high school teachers in a large, urban Kentucky school district. The mean number of high school teachers per school in this district was $96.41(S D=16.85)$. Once access to high school teachers was appropriately granted, teachers in each of the 18 high schools in the urban district were invited to participate in the study. An email was sent to all identified high school teachers to elicit participation in the present study.

In the $2017-18$ school year, there were $45.1 \%$ white students, $36.1 \%$ African American students, $10.5 \%$ Hispanic students, and 4.2\% students classified as other/two or more races. Additionally, $64.6 \%$ of the students qualify for the federal free/reduced lunch program, an indicator of socioeconomic status (KDE School Report Card, 2018).

\section{Instrumentation}


The survey instrument (Appendix B) selected for this research was adapted from Stiggins and Duke's (1988) TEP. Rindler (1994) revised the original TEP to include elements related to teacher evaluation (e.g., artifacts, student performance, selfevaluation, student evaluations, and peer observations). Doherty (2009) made additional revisions to the TEP to incorporate current methods of teacher evaluation. The original TEP included 55 closed-ended items in a questionnaire format designed to gain insight to teachers' experience with evaluation (Stiggins \& Nickel, 1988). Because the original TEP does not reference specific components of the Danielson Framework, a modified version of the TEP was used for the present study. Murray (2013) modified the TEP to include questions that reference the Danielson Framework. Specifically, questions about the training workshops for PGES, performance levels in PGES, and teaching standards in PGES were added.

The TEP was designed to collect information to improve teaching and learning at the school level and the modified version maintains the same goal (Forsyth, Barnes \& Adams, 2015). The original survey contains 71 survey questions and contains ten survey constructs with five to ten questions per construct. The constructs are as follows: Transformational Leadership Behavior, Organizational Citizenship Behavior, Teacher Workplace Isolation, Teacher/Leader Effectiveness, Collective Teacher Efficacy, Student Readiness to Learn, Critical Friends Group, Trust in District Administration, Faculty Trust in Parents, and Basic Information (Forsyth et al., 2015). Each construct uses a fivepoint Likert-type scale that includes the following choices: $1=$ Strongly Agree, $2=$ Agree, 3 = Neutral, 4= Disagree, $5=$ Strongly Disagree. 
The survey was a modified version of the TEP (Murray, 2013). Murray modified the TEP to include questions that reference the Danielson Framework by validating interview questions with an expert panel of teachers, administrators and curriculum specialists and approved by the research committee. Further, Murray (2013) modified the interview questions to assist in investigating the research questions. The semi-structured interview questions connected to the research questions and were designed to obtain a rich understanding of the subjects' perceptions of the new evaluation process as a method of improving professional practice and growth as an educator. The researcher piloted the interview questions during the fall of 2013. The teachers were asked to provide feedback pertaining to the quality of the wording, meaning, and interpretation of the interview questions.

Murray's (2013) modified survey maintains the five main categories from the TEP: a) attributes of the teacher, b) perceptions of the evaluator, c) attributes of the evaluation system, d) feedback received, and e) attributes of the evaluation context (Stiggins \& Nickel, 1988). Therefore, the reported internal consistency coefficient of 0.64 is in line with Cronbach (1951) who indicated that reliability coefficients about 0.60 , which is less than the .80 used in most research. Even though 0.64 is lower than what is used in some research, this survey was the correct instrument for the present research because the study asked questions specific to the Danielson Framework, which is the basis for PGES. In addition, the high estimate of internal consistency of the total instrument suggests that the scales of each attribute are both internally consistent and "highly correlated" (p. 51). Murray's (2013) modified version of the TEP was the appropriate instrument for the present study because the modifications include questions 
specific to the Danielson Framework. The Cronbach alpha for the questions used in this study was .97. In Kentucky, PGES was derived from the Danielson Framework making modified TEP the appropriate tool to gather data about teacher perception. The only demographic data collected were years of teaching experience to determine if there was a difference in perception among new and experienced teachers.

\section{Research Procedures}

Surveys were distributed electronically using Qualtrics survey software to teachers in the 18 district high schools. Self-administered surveys were used as they were a favorable form of data collection that is cost-effective and they allow respondents to maintain anonymity (McMillan \& Schumacher, 2010). A copy of the email sent to high school teachers is included in Appendix A. The survey provided a rationale and detailed directions to complete the survey, and included questions to identify the teachers' years of experience. The survey was sent to participants twice via email, with one week in between each mailing. An explanatory email provided information about the purpose of the study, information about how the results will be used, information about confidentiality and also contained the hyperlink to complete the survey. There was a one-

month window for participants to complete the survey. Participants who did not complete the survey after the first email had an additional one-month window to complete the survey, and were notified of the extra time in the follow up email.

\section{Statistical Procedures}


The survey addressed the following variables: years of experience (question 1), teacher perception of PGES (questions 5, 6, 7, 8, 9, 10, 11, 12, 17, 18, 19, 20), and teacher perception of administrative support for PGES (questions 2, 3, 4, 13, 14, 15, 16). These questions were selected because they address perception of PGES and administrative support. The selected questions ask perception questions that range in topic from definition of effective teaching, potential results after using PGES, accuracy of evaluations with PGES, and the overall value of PGES as it relates to teacher effectiveness. The mean was used to create three levels of both administrative support and perception of PGES: if the average of a participant's responses for these items was less than 2.50 then the teacher was categorized as having an unfavorable perception, if the average of a participant's responses for the items was between 2.50 and 3.49 then the teacher was categorized as having a neutral perception, and if the average of a participant's responses for the selected survey items was 3.50 or greater, the participant was categorized as having a favorable perception.

To address the research questions, both descriptive and inferential statistics were used. Descriptive statistics were used to address Research Question 1, teachers' perceptions of PGES. The proportion of teachers who responded negative, neutral or positive was computed. The frequencies within each category along with their respective percentages were reported. Reporting the proportion and frequency of their responses indicated a similar number of new and experienced teachers were surveyed. Also, the number of teachers with a positive perception of PGES outnumbered neutral or negative perceptions. The mean score of teachers' perceptions of PGES and the standard deviation were also calculated. 
To examine Research Question 2 (Is there a statistically significant difference in teachers' perception of PGES between teachers with a favorable perception of administrator support of PGES, teachers with an unfavorable perception of administrator support of PGES, and teachers who are neutral in their perception of administrator support of PGES?), the teachers' years of experience were categorized as "new" or "experienced" and the perceptions of PGES consisted of three categories of negative, neutral and positive. "Years of experience" was a closed-ended question with two answer choices: $0-3$ years teaching experience or more than three years' experience. Teachers with $0-3$ years teaching experience were categorized as new, and teachers with more than 3 years teaching experience were categorized as experienced. Several studies have estimated $33 \%$ of teachers leaving the profession within their first 3 years (Ingersoll, 2001; Kelley, 2004). Therefore, for the purposes of this study, teachers with $0-3$ years of experience were classified as "new" and teachers with more than 3 years of experienced were classified as "experienced." This question was answered using the main effects results of a factorial ANOVA where the independent variables were perceived administrative support and teacher experience and the dependent variable was perception of PGES.

Research Question 3, the difference in perceptions of PGES between new and experienced teachers, and Research Question 4, the interaction between administrative support and teachers' experience and perceptions of PGES, were also answered using this factorial ANOVA. Research Question 3 was answered using the main effects results of the factorial ANOVA and Research Question 4 was answered using the interaction effects of this model. For this study, between-subjects factorial ANOVA is appropriate 
because the factors are independent of one another. A factorial ANOVA model was used and factors were grouped the following way: teacher perception of administrative support of PGES (positive, negative, or neutral) and teacher years of experience (new, experienced). Between-subjects factorial design, or independent factorial design, is used to investigate research questions that "focus on the difference in the means of one dependent variable when there are two or more independent variables" (Field, 2014). This study is considered a two-way ANOVA because there are two independent variables: teacher perception of administrative support of PGES and years of teaching experience (Field, 2014). Further, this is a $3 \times 2$ factorial design because there are three levels of administrative support (positive, neutral, and negative) and two levels of experience (new and experienced). The outcome variable, teacher perception of PGES was the average of the selected survey questions that measured teacher perception of PGES. By selecting a factorial ANOVA to investigate the research questions, the researcher can examine the main effect, or the average across all the levels of all the other factors and the interaction effect, which investigates the effects of the various combinations of the independent variables (Field, 2014). Karpinski (2011) notes the main advantage of conducting multi-factor ANOVA designs is the ability to test different interactions. Using a factorial ANOVA helps avoided the risk of a Type I error that could occur with multiple ANOVA tests (Field, 2014).

A factorial ANOVA requires the independent variables to be categorical, while the dependent variable is continuous (Field, 2014). The variables for the present research included the teachers' perception of administrative support and the number of years' experience each teacher has completed. The dependent variable for this procedure was 
the teachers' perception of PGES. A factorial ANOVA examines both the main effects and the potential interaction between more than one variable. Significance was set at the .05 level because it is a commonly used criteria for hypothesis testing. Setting the significance at .05 will allow the researcher to determine if the variance between groups is larger than the variance within the groups. Further, this test allowed the researcher to look at the effects of more than one variable and how the variables interacted. A factorial ANOVA helped to determine if there was any interaction between years of teacher experience and teacher perception of administrative support. Educators with varying years of experience may have differing perspectives on new evaluation systems and administrative support.

The test was to determine if the factors of teachers' experience and teachers' perception of administrative support and the interaction of these two variables affect teachers' perception of PGES. For example, if there is a main effect then either teacher perception of administrative support of PGES or teacher years of experience has an effect on teacher perception of PGES. Further, an interaction effect would indicate that the interaction of years of experience and perception of administrative support of PGES affect teacher perception of PGES. The results of the factorial ANOVA were presented in the form of main effects and the interactions among study variables. If a significant interaction had been revealed, then a simple effects analysis would have been conducted. Simple effects analysis is characterization of the interaction to determine which differences are significant. Further, it is a comparison of the condition means for one level of the IV (teacher years of experience or teacher perception of administrative support of PGES). A Student-Newman-Keuls (SNK) post hoc test would have been 
conducted if significance was revealed. Cohen's $d$ is computed to measure effect size. Cohen's $d$ is an effect size used to indicate the standardized difference between two means. Cohen's $d$ is an appropriate effect size for the comparison between two means. Cohen suggested that $d=0.2$ be considered a 'small' effect size, 0.5 represents a 'medium' effect size and 0.8 a 'large' effect size (Field, 2014). This means that if two groups' means do not differ by 0.2 standard deviations or more, the difference is trivial, even if it is statistically significant. Cohen's $d$ is only reported when a significance is revealed.

A factorial ANOVA assumes a) a normal distribution of the data, b) homoscedasticity of error variances, and c) independence of the factors (Field, 2014). The assumptions of normality were checked with the one sample Kolmogorov Smirnov $(K S)$ test. Normality assumes that the error variance is normally distributed (symmetrical bell shaped). The null hypothesis for the $K S$ test is that groups were sampled from populations with identical distributions. Normality tests are only needed for small samples sizes and since the sample in this study is 330 respondents the test was not run. Homoscedasticity of variance assumes that both groups have equal error variances and was assessed using Levene's test (Field, 2014). The Levene's test measures the null hypothesis that variance is equal across all groups. A $p$ value greater than .05 indicates a violation and the null hypothesis of equal variances is rejected; the variances are not equal. In this study the Levene's test results, $F(38,272)=6.24, p<.001$ indicated the assumption of homoscedasticity of variance was not violated. The third assumption relates to the independence of the factors. A chi-square test was conducted on the variables of years of experience and the three levels of teachers' perceived administrative 
support to measure independence; $\chi^{2}(2)=70.62, p<.001$. In this case the null hypothesis was rejected and there was some association between these two variables.

\section{Assumptions}

As with any survey research, the researcher assumed all respondents were answering the questions truthfully and honestly. The hope was educators would see the value of this research and respond in an honest, professional manner. There was also an assumption that respondents were not under any undue pressure from their supervisors to respond in a particular manner. The procedures and protocols in place to ensure anonymity tried to alleviate the problem of supervisorial influence.

\section{Limitations of the study}

Threats to internal and external validity included: the instrumentation, maturation, and selection (Cook \& Campbell, 1979). Threats to the instrumentation included the fact the survey measures perception only, not factual information. The survey is measuring teachers' perceptions of administrative support and their perceptions of the implementation of PGES. Maturation threats included the level of implementation at the school level. The survey asked participants to address the level of implementation in his or her school. Implementation at the school level could have been affected by a change in administration mid-year or other disruptions to the school. Finally, the internal validity threat includes the selection process for participants (Field, 2014). Teachers from $18 \mathrm{high}$ schools in JCPS were included in this study to address this aspect of internal validity. All high schools within this district were represented and the sample of 330 respondents exceeded the $10 \%$ rule of thumb set forth by Creswell in 2014. A possible limitation is 
the use of convenience sampling. Specifically, convenience sampling is vulnerable to selection bias and influences beyond the control of the researcher. This could, in turn, lead to sampling errors.

External threats to validity in this study include: reactive effects of experimental arrangements, generalizability, and population representation (Cook \& Campbell, 1979). Reactive effects of experimental arrangements were addressed by eliminating any identifying information from the survey. Respondents were guaranteed complete anonymity when completing the online survey. Generalizability (Cook \& Campbell, 1979) and population representations threats were addressed by including multiple high schools in the study. Including teachers at high schools within the urban district in this study may large enough to generalize results to similar districts. However, the demographic data of the selected district should be considered before generalizing the data to other districts. Since the district used in the study was a large metropolitan school district with a very diverse heterogeneous population these results may be generalizable to the convenience sample of responding teachers in a single, large urban school district for the time period in which the survey was implemented.

\section{Potential Implications}

The findings of this study may inform administrators about high school teachers' perceptions of administrator support with PGES and teacher perceptions of how PGES can be used as a tool to improve instruction. Providing administrators with current perception data for teachers about PGES may allow for a more responsive approach to professional development opportunities and support for teachers with varying years of 
teaching experience. Conducting a survey to investigate teachers' perceptions of administrative support may provide opportunities for growth for teachers and administrators using the Professional Growth and Effectiveness System. Student achievement is best supported in environments with effective leaders. Administrators who are instructional leaders can improve student outcomes (Kolzow, 2014). If effective feedback to support teacher growth can benefit student achievement, it is incumbent upon administrators to stay abreast of teacher evaluation trends. Not only must administrators stay abreast of teacher evaluation trends, they must also communicate effective feedback to teachers based on the evaluation model. Understanding teachers' perceptions of administrative support of an evaluation model will help administrators adjust feedback and support. The results of this study may have implications for teachers as well because they will provide specific feedback from teachers on the perceptions of administrative support with the implementation of PGES. 


\section{CHAPTER IV}

\section{RESULTS}

The present study examined the high school teachers' perception of PGES and high school teachers' perceptions of administrative support of PGES. Another purpose of this study was to investigate the relationship between years of teaching experience and perception of PGES. The chapter outlines the results of the survey as they relate to the research questions. As stated in earlier chapters, this study examined how new and experienced teachers in an urban school district in Kentucky perceive support from their school administrators under the current teacher evaluation system. Specifically, it sought to answer the following research questions:

1. What are teachers' perceptions of the Professional Growth and Effectiveness System (PGES)?

2. Is there a statistically significant difference in teachers' perception of PGES between teachers with a favorable perception of administrator support of PGES, teachers with an unfavorable perception of administrator support of PGES, and teachers who are neutral in their perception of administrator support of PGES?

3. Is there a statistically significant difference in the perception of PGES between new and experienced teachers? 
4. Is there an interaction between teachers' perceptions toward administrative support and experience and their perceptions of PGES?

This chapter begins with a brief descriptive analysis of all study variables. Next, a two-way factorial analysis of variance was conducted to explore the relationships between all study variables. The chapter is thereafter organized by research question, discussing the separate analyses and results for each. A summary of key findings is offered at the conclusion of the chapter.

\section{Survey Responses}

For this study, the targeted population was high school teachers $(n=1,728)$ in one large urban school district in Kentucky. Out of the total target population of 1,728, 336 teachers responded to the survey, making the response rate $19.4 \%$. Of the 336 teachers who began the survey, six left at least one question blank. Incomplete surveys were not included in the analysis. After removing the incomplete surveys, there were 330 responses (19.0\%); the teacher response rate was higher than the average online response rate of 10 to $15 \%$ (Field, 2014).

\section{Teacher perception of administrative support of PGES}

Table 1 reports the descriptive statistics for teacher perception of administrative support of PGES divided by level. Teacher perception of administrative support of PGES, was grouped into three categories: positive, negative, and neutral. Of the 330 teachers who participated in the study, $25.70 \%$ of teachers had a negative perception of administrative support of PGES, $23.60 \%$ had a neutral perception of administrative support of PGES, and $50.60 \%$ had a positive perception of administrative support of 
PGES. The mean score for perceived administrative support was $3.22(S D=.89)$. The value of 3.22 is within the neutral range for teachers' perception of administrative support. On the average, teachers had a neutral view of the administrative support of PGES.

Table 1

Perceived Administrative Support of PGES

\begin{tabular}{ccc}
\hline Administrative Support & Frequency & $\%$ \\
Negative (0-2.49) & 85 & 25.80 \\
Neutral (2.5-3.49) & 78 & 23.60 \\
Positive (3.50- 5.0) & 167 & 50.60 \\
Total & 330 & 100.00
\end{tabular}

Note. Administrative Support $=$ Administrative support for PGES; Frequency $=$ Number of teachers whose mean score for perception of administrative support fell into each category; $\%=$ Percentage of teachers who fit into each category

\section{Teacher years of experience}

Teacher years of experience, was grouped into two categories: new and experienced. A teacher's response to question 1 determined whether a teacher would be categorized as new or experienced. Survey question 1 asked how many years the teacher had been teaching, including the current year. The answer choices were " $0-3$ years" and "more than 3 years." Teachers who selected " $0-3$ years" were categorized as new and teachers who selected "more than 3 years" were categorized as experienced. For this study, 143 teachers $(43.30 \%)$ were categorized as new and 187 teachers $(56.70 \%)$ were categorized as experienced. 


\begin{abstract}
Analysis
Research Question 1: What are teachers' perceptions of the Professional Growth and Effectiveness System (PGES)?

To answer question one about teachers' perceptions of PGES, descriptive statistics were used. To determine each teacher's perception of PGES, select questions from the survey were averaged. Of the 330 teachers who participated in the study, $20.30 \%$ of teachers had a negative perception of PGES, $30 \%$ had a neutral perception of PGES, and $49.70 \%$ had a positive perception of administrative support of PGES. The mean score of teacher perception of PGES was $3.29(S D=.82)$. A mean score of 3.29 was equivalent to teachers holding a neutral position on PGES. These results become important for further examination of how teachers perceive the FfT tool used in PGES. The survey questions required participants to consider the function of evaluation and reflection and whether or not the FfT is a valid measure of teacher effectiveness.

Research Question 2: Is there a statistically significant difference in teachers' perception of PGES between teachers with a favorable perception of administrator support of PGES, teachers with an unfavorable perception of administrator support of PGES, and teachers who are neutral in their perception of administrator support of PGES?
\end{abstract}

This question was addressed using a factorial ANOVA. Teachers who had a negative view of administrative support had a mean perception of PGES of $2.25(S D=$ 49). Teachers who had a neutral view of administrative support had a mean of 3.08 (SD $=.45)$ in terms of their perception of PGES. Teachers who had a positive view of administrative support had a mean of $3.91(S D=.37)$. The results are shown in Table 2 . 
Table 2

Means of Teachers' Perceptions of PGES between Administrative Support Groups \begin{tabular}{llll}
\hline Administrative Support & Mean & N
\end{tabular}

\begin{tabular}{llcr}
\hline Negative & 2.25 & .49 & 85 \\
Neutral & 3.08 & .45 & 78 \\
Positive & 3.91 & .37 & 167 \\
\hline
\end{tabular}

Note. Administrative Support $=$ Administrative support of PGES; Mean $=$ Mean perception of PGES; $S D=$ standard deviation; $\mathrm{n}=$ number

The factorial ANOVA results indicated there was a significant main effect of administrative support on teachers' perceptions of PGES, $\mathrm{F}(2,324)=48.21, p<.001$, suggesting that people with higher perceptions of administrative support had higher perceptions of PGES. A post hoc analysis was conducted using the Tukey test. The results of the Tukey test revealed the differences between the negative perceptions and both the neutral and positive perceptions were significant and the difference between the 
neutral and positive perceptions was significant. The partial eta squared of .63 indicated $62.7 \%$ of the variance can be explained by the teachers' perceptions of administrative support. The Cohen's $d$ between negative and neutral was 1.76 ; between negative and positive was 2.01 and between positive and neutral was 2.01. These values indicated administrative support had a large effect on teachers' perceptions of PGES.

Research Question 3: Is there a statistically significant difference in the perception of PGES between new and experienced teachers?

This question is about the difference in new and experienced teachers' perceptions of PGES was addressed using a factorial ANOVA. The mean teacher perception score of PGES for new teachers was $3.70(S D=.63)$ and the mean score for experienced teachers was $2.99(S D=.81)$ as shown in table 3 .

Table 3

Means of Teachers' Perceptions of PGES and Years of Experience

Experience $\quad$ Mean $\quad S D$

New

3.70

.63

143

Experienced

2.99

.81

187

A factorial ANOVA was conducted to see if teacher experience was a main effect of teachers' perception of PGES. The factorial ANOVA revealed there was no main effect of experience on the teachers' perceptions of PGES, $F(1,324)=.17, p>.05$, with a partial eta squared, reporting that less than $1 \%$ of the variance explained by the 
teachers' years of experience.

Research Question 4: Is there an interaction between teachers' perceptions toward administrative support and teachers' experience and teachers' perceptions of PGES?

This question is about the interaction effects between teachers' experience, teachers' perceived administrative support of PGES and teachers' perception of PGES, and a factorial ANOVA was conducted. The descriptive statistics for the factorial ANOVA are reported in Table 4 . New teachers who had a negative perception of administrative support had a mean score of $2.14(S D=.44)$ for their perception of PGES, those who had a neutral view of administrative support had a mean score of $3.11(S D=$ $.50)$, and those with a positive perception of administrative support had a mean of $3.97(S D=.24)$. Experienced teachers who had a negative perception of administrative support had a mean score of $2.27(S D=.50)$ for their perception of PGES, those who had neutral perception of administrative support had a mean of $3.08(S D=.43)$ and those who had a positive perception of administrative support had a mean of $3.81(S D=.53)$.

Levene's Test indicated no significance for the interaction between teacher perception of PGES and teacher years of experience $(p<.001)$. There was also not a significant interaction effect between the two factors of experience and administrative support, $F(2,324)=2.08, p>.05$, with partial eta squared reporting that $1.10 \%$ of the variance can be explained by the interaction between the teachers' perception of administrative support and teachers' years of experience. 
Table 4

Teachers' Perceptions of PGES by Experience and Administrative Support

\begin{tabular}{|c|c|c|c|c|}
\hline \multirow[t]{2}{*}{ Experience } & Adminsup & Mean & \multirow{2}{*}{\multicolumn{2}{|c|}{$N$}} \\
\hline & & & & \\
\hline \multirow[t]{4}{*}{ New } & Negative & 2.14 & .44 & 11 \\
\hline & Neutral & 3.11 & .50 & 23 \\
\hline & Positive & 3.97 & .27 & 109 \\
\hline & Total & 3.70 & .63 & 143 \\
\hline \multirow[t]{4}{*}{ Experienced } & Negative & 2.27 & .50 & 74 \\
\hline & Neutral & 3.08 & .43 & 55 \\
\hline & Positive & 3.81 & .53 & 58 \\
\hline & Total & 2.99 & .81 & 187 \\
\hline \multirow[t]{3}{*}{ Total } & Negative & 2.26 & .49 & 85 \\
\hline & Neutral & 3.08 & .45 & 78 \\
\hline & Positive & 3.92 & .37 & 167 \\
\hline
\end{tabular}




\section{Summary}

The comparisons of the percentages of teachers who had a negative perception of PGES, $20.30 \%$, to those with a neutral perception, $30 \%$, to those with a positive perception of PGES, $49.70 \%$, indicated a significant percentage of teachers have a positive perception of PGES. Furthermore, teachers who had a more positive view of administrative support had a higher perception of PGES. Results of the survey reveal teachers' perception of administrative support affect their perception of PGES. Teachers who have a favorable perception of administrative support are likely to have a favorable perception of PGES. New teachers tended to have a more favorable perception of PGES than experienced teachers. Of the factors considered to affect teachers' perceptions of PGES, the teachers' perception of administrative support had a main effect while years of experience and the interaction of between administrative support and years of experience did not have an effect of teachers' perception of PGES. 


\section{CHAPTER V \\ DISCUSSIONS AND CONCLUSIONS}

This study examined the relationship between teacher perception of administrative support of PGES, teacher years of experience and teacher perception of PGES. The study was necessary because of the changes to the evaluation system in Kentucky. Similar to thirty-six other states who have revised teacher evaluation policies since 2009, Kentucky's adoption of PGES caused teachers and administrators to rethink evaluation for teachers (National Council on Teacher Quality, 2012). There is no definitive evidence to determine whether the teacher evaluation process is an accurate gauge of teacher effectiveness. The purpose of this study was to investigate teachers' perceptions of the current teacher evaluation system, PGES, which is based on the Danielson Framework for Teaching. A previous study (Murray, 2013) examined teacher perception of PGES at the elementary school level, and the present study provides an extension to that research by examining high school teachers. This chapter provides conclusions from the study as well as a discussion of how the findings may support administrators as they decide to continue with PGES or seek new evaluation models. Previous studies on teacher evaluation do not clearly connect the quality of administrator feedback to improved instruction or changed instructional practices. It is important for administrators to understand how to best support teachers. To help fill the gap in existing literature on teacher evaluation, this study sought to explore teachers' perceptions of 
evaluation in relation to administrator support and years of experience because teacher evaluation continues to dominate education policy plans and decisions. The research questions are as follows:

1. What are teachers' perceptions of the Professional Growth and Effectiveness System (PGES)?

2. Is there a statistically significant difference in teachers' perception of PGES between teachers with a favorable perception of administrator support of PGES, teachers with an unfavorable perception of administrator support of PGES, and teachers who are neutral in their perception of administrator support of PGES?

3. Is there a statistically significant difference in the perception of PGES between new and experienced teachers?

4. Is there an interaction between teachers' perceptions toward administrative support and experience and their perceptions of PGES?

\section{Conceptual Framework and Limitations}

The conceptual framework for the present study included teacher perception of PGES and teacher years of experience as factors. A conceptual framework is contextualizes a study and allows for a more thorough understanding of the variables being researched (Imenda, 2014). Teachers' perceptions of administrative support of PGES were a primary focus of this study. Whether teachers had a positive, negative, or neutral perception of how well they felt administrators supported them was important to measure while exploring teacher perception of PGES. Further, categorizing teachers by years of experience allowed the researcher to determine whether how much experience a 
teacher has impacts his or her perception of administrative support of PGES.

Limitations in the study include an unequal sample size for one independent variable, teacher perception of PGES. A possible limitation is the use of convenience sampling. Specifically, convenience sampling is vulnerable to selection bias and influences beyond the control of the researcher. This could, in turn, lead to sampling errors. Since the district used in the study was a large metropolitan school district with a very diverse heterogeneous population these results may be generalizable to the convenience sample of responding teachers in a single, large urban school district for the time period in which the survey was implemented.

Teachers overwhelmingly had a favorable view of PGES, based on survey responses. There were 164 teachers who were categorized as having a positive perception of PGES, 99 teachers who were neutral, and 67 teachers who were negative. The difference between groups is a limitation because one group should not be more than 1.5 times larger than another group (Field, 2011). In this case, the category of teachers with a positive perception of PGES $(n=164)$ is more than 1.5 times larger than teachers with a negative perception of PGES $(n=67)$. This is a limitation because the groups are not equally divided between positive and negative perceptions. To further build on the current research, future studies should survey groups that are more evenly divided between positive and negative perceptions. Another limitation was the format of survey distribution. There may have been more teachers respond if the survey was given in person rather than online. The response rate $(10 \%)$ may have been increased if the surveys were administered at teachers' schools. 
As school districts in Kentucky grapple with evaluation and possible changes to the current evaluation system, the present study provides a context to support administrators as they make key policy decisions about teacher evaluation. Danielson's FfT has reshaped evaluation for educators nationwide. Although many teachers have a favorable opinion about the usefulness of the current evaluation system, PGES continues to spark controversy. As policy makers explore options for evaluation, it is relevant to understand the impact of PGES.

\section{Summary of Results}

Previous studies on teacher evaluation that investigated teacher perception of administrative support were inconclusive (Murray, 2013). Because PGES is an SBTE and more SBTE systems have been implemented across the country, the present study sought to explore teacher perceptions of administrator support in the SBTE, specifically PGES. With the passage of ESSA, evaluation continues to evolve. It is important to consider PGES as the state moves forward and districts consider whether to continue using PGES or adopt a new evaluation system. Understanding teacher perceptions of administrator support of evaluation is important now because regardless of which evaluation system is selected, administrators have to be prepared to lead teachers and help them improve instruction. According to the findings of this study, teachers generally understand the purpose of evaluation and the need to have a supportive administrator. It will be important for teachers to continue making connections between effective instruction and student achievement. School leaders need to support teachers in their development by providing them effective feedback to help shape and improve their instruction.

The first finding of the present study is a result of the analysis of survey data and 
descriptive statistics. Analysis of survey questions that measured teacher perception of PGES was conducted with a factorial ANOVA. The mean score of the responses to survey questions about teacher perception of PGES was $3.29(S D=.82)$, meaning teacher averaged a neutral position on PGES. The survey questions that measured perception of PGES required participants to consider the function of evaluation and reflection and whether or not the FfT is a valid measure of teacher effectiveness.

The second research question was addressed with the selected survey responses (Is there a statistically significant difference in the level of perceived administrative support between teachers with a favorable perception of PGES, teachers with an unfavorable perception of PGES, and teachers who are neutral in their perception of PGES?). Results from the survey indicate no statistically significant difference in the perceived administrative support between teachers with positive, negative, or neutral perceptions of PGES. Survey questions 2, 3, 4, 13, 14, 15, 16 addressed components of evaluation specific to administrative support. For example, question 2 asked respondents about the training provided by the administration to support teacher evaluation. Fortynine percent of teachers agreed that their administrator provided adequate training for teacher evaluation. Another item addressed feedback about evaluation from the administrator. For this item, $58.5 \%$ of teachers either agreed or strongly agreed that feedback from their principal provides them with specific comments related to teaching standards addressed in the evaluation. Analysis of the data did not indicate that a teacher's perception of administrative support of PGES was associated with his or her perception of PGES.

The third research question, (Is there a statistically significant difference in the 
level of perceived administrative support between new and experienced teachers?), also did not indicate a statistically significant difference between perception of PGES and years of experience. Teachers were categorized by years of experience. Teachers who have been teaching $0-3$ years were categorized as "new" and teachers with more than 3 years were categorized as "experienced." The possible interaction effect between teacher perception of administrative support of PGES and teacher years of experience were analyzed in order to determine if either variable impacts teacher perception of administrative support. Although one factor (perception of administrative support of PGES) was statistically significant, there was not a significant interaction between the two factors. There was no statistically significant difference between new and experienced teachers and their perceptions of administrative support of PGES.

The fourth research question (Is there an interaction between teachers' perceptions toward administrative support and experience and their perceptions of PGES?) did not indicate significance. However, the results of this research suggest that teachers with a more favorable perception of administrative support of PGES also have a more favorable perception of PGES. This finding may benefit administrators as they plan to support teachers throughout the evaluation process. Professional development opportunities and feedback sessions with teachers may help teachers understand the evaluation process and purpose more thoroughly and improve instructional performance. The first research question (What are teachers' perceptions of the Professional Growth and Effectiveness System (PGES)?) included analyzing survey questions 5, 6, 7, 8, 9, 10, $11,12,17,18,19,20$. Teachers agree $(55.4 \%)$ or strongly agree $(8.6 \%)$ that they have a thorough understanding of the performance levels in PGES. Further, teachers agree 
$(55.7 \%)$ or strongly agree $(4.4 \%)$ that the definition of effective teaching as outlined by PGES aligns with their personal beliefs about effective teaching. Teachers agree (48.5\%) or strongly agree (3.3\%) that PGES will lead to significant changes in improving teaching practice. This indicates a belief among many teachers that PGES is an effective evaluation measure for teachers. Teachers also indicated that PGES provides an accurate assessment of their teaching performance. Generally, teachers reported a neutral perception of PGES. The results of the teacher perception of PGES are similar to previous studies of teacher perception of PGES (Murray, 2014). Further, there was no interaction effect between teacher perception of administrative support of PGES and teacher years of experience with teacher perception of PGES.

\section{Implications for Future Research}

The results of the research were inconclusive as to whether or not a teacher's perception of administrative support of PGES helped shape a teacher's perception of PGES. Further, the results did not indicate that a teacher's years of experience influenced his or her perception of PGES. Future researchers may replicate this research over multiple years to find potential trends for either perception of administrator support or years of experience. An additional expansion of the present research could include the number of years of administrative experience. New administrators and experienced administrators may contribute differently and that consideration may be a relevant data point for teacher perception of PGES. Another way to explore administrator perception would be to include interview data. Including interview data may provide more in depth contextual information about PGES. Understanding more about a principal's perception of PGES in relation to a teacher's perception of PGES may shed light on any relationship 
between the two factors. Another extension of the present research could include comparing student achievement data to teachers' perception of PGES. This extension of the research could allow future researchers to determine if a teacher's perception of PGES could impact student achievement. Further, including a larger sample size could help improve the reliability of the results. As principals consider their impact on student achievement, a more thorough understanding of how the evaluation system, PGES, can help leaders make more informed decisions on professional development and levels of support for teachers.

\section{Conclusion}

This study sought to explore teachers' perceptions of PGES. Specifically, the study looked for any relationship between teachers' perceptions of administrative support of PGES, teachers' years of experience, and teacher perception of PGES. Although the results did not indicate an interaction between teachers' perceptions of administrative support of PGES, teachers' years of experience, and teachers' perception of PGES, the findings did suggest teachers' perceptions of administrative support were significant. The large, urban school district in Kentucky, where the study was conducted, was five years into the adoption of PGES. The system has been in place for several years and administrators have had significant time to provide training and support for teachers.

Previous studies (e.g., FILL) sought to quantify teacher behaviors in order to provide specific feedback to teachers, which may influence student achievement. Brophy and Evertson (1973) found correlations between increased student achievement and behaviors such as asking higher level questions, calling on random students, avoiding absences, and providing specific feedback. Further, Hattie (2009) added that if teaching 
and learning are visible, student achievement increases. By exploring how teachers perceive support from their administrator on evaluation, the present study can assist administrators as they plan to provide effective feedback to teachers through PGES. Moreover, teacher evaluation policy could help improve teacher instruction (Weber, 1987). More importantly, "establishing a strong link between teacher evaluation and professional development would be a step forward in meeting the nation's goal of placing quality teachers in every classroom" (Munoz \& Dossett, 2016, p. 124). The present study suggests that teachers' perceptions of administrative support have some influence over the way teachers perceive PGES. This is a relevant finding because it can inform administrators on the importance of their leadership with the evaluation system. 


\section{REFERENCES}

Amrein, A. L., \& Berliner, D. C. (2002). High-stakes testing, uncertainty, and student learning. Education Policy Analysis Archives, 10(18).

Attinello, J., Lare, D., \& Waters, F. (2006). The value of teacher portfolios for evaluation and professional growth, NASSP Bulletin, 90(2), 132-152.

Bogart, Christopher D. (2013). Teacher evaluation and classroom practice: Teacher perceptions in northeast Tennessee. (Doctoral dissertation). Retrieved from http://dc.etsu.edu/etd/1177

Borman, G. D. \& Kimball, S.M. (2005). Teacher quality and educational equality: Do teachers with higher standards - based evaluation ratings close student achievement gaps? The Elementary School Journal. 106(1) 3-20. doi: $10.1086 / 496904$

Boyd, R. T. C. (1989). Improving teacher evaluations. Practical Assessment, Research \& Evaluation. 1(7). Retrieved from http://pareonline.net/getvn.asp?v=1\&n=7 
Brooks, J., \& Brooks, M. (1999). In search of understanding: The case for constructivist classrooms. Alexandria, VA: Association of Supervision and Curriculum Development.

Brophy, J., \& Evertson, C. (1973). Low-inference observational coding measures and teacher effectiveness. Washington, D.C.: National Institute for Education.

Cantrell, S., \& Kane, T. (2013). Ensuring fair and reliable measures of effective teaching: Culminating findings from the MET project's three-year study. Retrieved from The Met Project website: http://www.metproject.org/downloads/MET_Ensuring_Fair_and_Reliable_Measu res_Practitioner_Brief.pdf

Cooper, A., Levin, B., \& Campbell, C. (2009). The growing (but still limited) importance of evidence in education policy and practice, Journal of Educational Change, 10(23), 159-171.

Creswell, J. W. (2009). Research design: Qualitative, quantitative, and mixed methods approaches. Los Angeles: Sage.

Danielson, C. (2016). The Framework. Retrieved from Danielson Group website: https:/www.danielsongroup.org/framework/

Danielson, C. (2010). Danielson Group. Measures of Effective Teaching (MET) Project. Retrieved from http://eric.ed.gov/?id=ED540958 
Danielson, C. (2007). Enhancing professional practice: A framework for teaching. Association for Supervision and Curriculum Development. Retrieved from http://catdir.loc.gov.echo.louisville.edu/catdir/toc/ecip0620/2006030286.html

Danielson, C. \& McGreal, T. (2000). Teacher evaluation to enhance professional practice. Association of Supervision and Curriculum Development. Retrieved from http://www.ascd.org/publications/books/100219.aspx

Darling-Hammond, L., Wise, A., \& Pease, S. (1983). Teacher evaluation in the organizational context: A review of the literature. RAND Corporation. doi: $10.3102 / 00346543053003285$

Derrington, M.L., \& Campbell, J. (2015). Principal concerns and superintendent support during teacher evaluation changes. AASA Journal of Scholarship and Practice, 12(3) $11-21$. Retrieved from http://www.aasa.org/uploadedFiles/Publications/JPS-Fall2015.FINAL.v3.pdf

Desimone, L. (2002). How can comprehensive school reform models be successfully implemented? Review of Education Research, 72(3), 433-479.

Donaldson, M. (2012). Teachers' perspectives on evaluation reform. Center for American Progress. Retrieved from https://cdn.americanprogress.org/wpcontent/uploads/2012/12/TeacherPerspectives.pdf

Doherty, J. F. (2009). Perceptions of teachers and administrators in a Massachusetts suburban school district regarding the implementation of a standards-based 
teacher evaluation system. (Unpublished doctoral dissertation). Seton Hall University, New Jersey.

DuFour, R., \& Mattos, M. (2013). How do principals really improve schools? The Principalship, 70(7), 34-40.

Ellett, C. D., \& Teddlie, C. (2003). Teacher evaluation, teacher effectiveness and school effectiveness: Perspectives from the USA. Journal of Personnel Evaluation in Education, 12(1), 101-128.

Fensterweld, J. (2015). Half of new teachers leave profession after 5 years? New study says not true. EdSource. Retrieved from https://edsource.org/2015/half-of-newteachers-quit-profession-in-5-years-not-true-new-study-says/83054

Field, A. (2013). Discovering statistics using IBM SPSS statistics. London: Sage Publications.

Finkel, E. (2012). Principals as instructional leaders. District Administration, 48(6), 50.

Fontanilla, H.S. (2015). Comparison of beginning teachers' and experienced teachers' readiness to integrate technology as measured by TPACK scores. (Unpublished dissertation). Brandman University: California

Forsyth, P.B., Barnes, L.B., \& Adams, C.M. (2006). Trust effectiveness patterns in schools. Journal of Educational Administration. 44(2) 122-141. 
Fowler, F. (2009). Using survey research. Thousand Oaks, California: SAGE Publications.

Fullan, M. (2001). Leading in a culture of change. San Francisco: Jossey-Bass.

Gardner, H. (1983). Frames of Mind. New York: Basic Books Inc.

Gay, L. R., Mills, G. E., \& Airasian, P. W. (2009). Educational research: Competencies for analysis and applications. New Jersey: Prentice Hall.

Goe, L., Little, O., \& Bell, C. (2009). A practical guide to evaluating teacher effectiveness. Retrieved from The National Comprehensive Center for Teacher Quality website https://files.eric.ed.gov/fulltext/ED543776.pdf

Goldhammer, R. (1969). Clinical supervision: Special methods for the supervision of teachers. New York: Holt, Rinehart, and Winston.

Hallinger, P., Heck R., \& Murphy, J. (2014). Teacher evaluation and school improvement: An analysis of the evidence. Educational Assessment, Evaluation and Accountability, 26(1), 5-28.

Halverson, R. (2004). Accessing, documenting, and communicating practical wisdom: The phronesis of school leadership practice. American Journal of Education, 111, $1,90-121$. Retrieved from http://www.jstor.org/stable/10.1086/424721?seq=1\#page_scan_tab_contents 
Halverson, R., Kelley, C., \& Kimball, S. (2004). Implementing teacher evaluation systems: How principals make sense of complex artifacts to shape local instructional practice. Research and Theory in Educational Administration, 153 188. Retrieved from http://dm.education.wisc.edu/rrhalverson/intellcont/\%20RTEA\%20halversonkelle ykimball\%20110707-1.pdf

Haixia, S., \& Ye, L. (2011). Comparative study of the new and experienced teachers' differences in the general teaching of mathematics. Journal of Mathematics Education. 14(2) 71-79

Hallinger, P., Heck, R. H., \& Murphy, J. (2014). Teacher evaluation and school improvement: An analysis of the evidence. Education, Evaluation, Assessment and Accountability. doi:10.1007/s11092-013-9179-5

Hattie, John. (2012). Visible learning for teachers: maximizing impact on learning. New York, NY: Routledge

Hazi, H., \& Rucinski, D. (2009). Teacher evaluation as a policy target for improved student learning: a fifty-state review of statute and regulatory action since NCLB. Education Policy Analysis Archives. Retrieved from http://epaa.asu.edu/ojs/article/view/7

Ingle, W.K., \& Wisman, A. (2018). Revisiting and extending the work of Cowen and Fowles: A historical analysis of Kentucky teacher contracts. Educational Policy $32(2), 313-333$. 
Institute of Education Sciences U.S. Department of Education (2007). Examining district guidance to schools on teacher evaluation policies in the Midwest region (Publication 030). Washington DC: Brandt, C., Mathers, C., Oliva, M., BrownSims, M., \& Hess, J

Interstate New Teacher Assessment and Support Consortium, Model Standards for Beginning Teacher Licensing (1992). Assessment and Development: A Resource for State Dialogue. Retrieved from http://programs.ccsso.org/content/pdfs/corestrd.pdf

Jensen, B., et al. (2012), The experience of new teachers: Results from TALIS 2008. OECD Publishing. http://dx.doi.org/10.1787/9789264120952-en

Jerald, C. (2012). Ensuring accurate feedback from observations. Retrieved from the Gates Foundation website: http://www.gatesfoundation.org/college-readyeducation/Documents/ensuring-accuracy- wp.pdf

Johnson, S. (1980). Performance-based layoffs in the public schools: Implementation and outcomes. Harvard Educational Review, 50, 2. Retrieved from http://gse.buffalo.edu/fas/Jacobson/629/pdffiles/b025320155.pdf

Kilgore, S. B., \& Reynolds, K. J. (2011). From silos to systems: Reframing schools for success. Thousand Oaks, CA: Corwin

Kimball, S. (2001). Innovations in teacher evaluation: Case studies of two school districts with teacher evaluation systems based on the framework for teaching 
(Doctoral dissertation). Retrieved from ProQuest Dissertations and Theses database. (UMI No. 3033269)

Kimball, S., White, B., Milanowski, A., \& Borman, G. (2004). Examining the relationship between teacher evaluation and student assessment results in Washoe County. Peabody Journal of Education, 79(4), 54-78.

Klein, Alyson. (2017). No child left behind overview: Definitions, requirements, criticisms, and more. Education Week. Retrieved from https://www.edweek.org/ew/section/multimedia/no-child-left-behind-overviewdefinition-summary.html

Leithwood, K., Patton, S., \& Jantzi, D. (2010). Testing a conception of how school leadership influences student learning. Educational Administration Quarterly, 46(5) 671 - 706. doi: 10.1177/0013161X10377347

Lindle, J. C. (2001). Teaching and learning: Curriculum, the Kentucky Department of Education, and the educational professional standards board. Frankfort, KY: Frankfort, KY: Kentucky Institute on Education Research and the UK/UL Jt. Ctr. for the Study of Educational Policy. Retrieved from http://tigerprints.clemson.edu/cgi/viewcontent.cgi?article=1056\&context=eugene pubs

Manatt, R., \& Daniels, B. (1990). Relationships between principals' ratings of teacher performance and student achievement. Journal of Personnel Evaluation in Education 4(2), 189-201. 
Marchant, G. J., David, K.A., Rogers, D., German, R.L. (2015). State teacher evaluation and teacher education. Teacher Educator, 50, 89-108.

Mathers, C., \& Oliva, M. (2008). Improving instruction through effective teacher evaluation: Options for states and districts. National Comprehensive Center for Teacher Quality. Retrieved from http://eric.ed.gov/?id=ED520778

Marko, D., Macia, L., \& Lee, H. (2013). Challenges for school leadership: A survey of teachers and principals. MetLife Inc. Retrieved from https://www.metlife.com/assets/cao/foundation/MetLife-Teacher-Survey2012.pdf

Marzano, R. J., Frontier, T., \& Livingston, D. (2011). Effective supervision: Supporting the art and science of teaching. Alexandria, VA: ASCD.

McCaffrey, D., Lockwood, J., Koretz, D., \& Hamilton, L. (2003). Evaluating valueadded models for teacher accountability. RAND Corporation. Retrieved from http://eric.ed.gov/?id=ED529961

McGuinn, P. (2012). The state of teacher evaluation reform. Retrieved from The Center for American Progress website: https://files.eric.ed.gov/fulltext/ED539744.pdf

Milianowski, A. (2004). The relationship between teacher evaluation scores and student achievement: Evidence from Cincinnati. Peabody Journal of Education, 33 - 53

Milanowski, A.T. \& Heneman, H.G. Journal of Personnel Evaluation in Education (2001) 15: 193. doi:10.1023/A:1012752725765 
Munoz, M. \& Dossett, D. (2016). Multiple measures of teaching effectiveness:

Classroom observations and student surveys as predictors of student learning. Planning and Changing, 47(3/4), 123 - 140.

Murray, P.K. (2014). An investigation of teacher and administrator perceptions of Pennsylvania's new teacher evaluation system, based upon the Danielson framework for teaching, and its impact on teachers' instructional strategies in an urban school (Doctoral dissertation). Retrieved from UMI Dissertation Publishing. (UMI Number: 3645758).

Nachazel, T., \& Hannes, G. (2011). The condition of education. Retrieved from the Institute of Educational Sciences website: https://nces.ed.gov/pubs2011/2011033.pdf

National Commission on Excellence in Education. (1983). A nation at risk: The imperative for educational reform: a report to the Nation and the Secretary of Education, United States Department of Education. Washington, D.C.: United States Government Printing Office.

National Council on Teacher Quality. (2012). Navigating the race to the top traffic jam. Retrieved from https://eric.ed.gov/?id=ED512683

Loup, K., Garland, J., Ellett, C., \& Rugutt, J. (1996). Ten years later: Findings from a replication of a study of teacher evaluation practices in our 100 largest school districts. Journal of Personnel Evaluation in Education, 10(3), 203-226. 
Odden, A. (2004). Lessons learned about standards-based teacher evaluation systems. Peabody Journal of Education, 79, 4.

Peterson, K. (2000). Teacher evaluation: A comprehensive guide to new directions and practices $\left(2^{\text {nd }}\right.$ ed.). Thousand Oaks, CA: Corwin Press.

Peterson, K. (2004). Research on school teacher evaluation. NASSP Bulletin, 88, 639.

Piaget, J. (1952). The origins of intelligence in children. New York, New York: International Universities Press.

Pizzi, J.D. (2009). Urban secondary teachers' perceptions of a standards-based teacher evaluation system. (Unpublished doctoral dissertation). Boston College. Boston, MA.

Rindler, B. (1994). The attributes of teacher evaluation systems that promote teacher growth as perceived by teachers of intensive English programs. (Unpublished doctoral dissertation). Boston College. Boston, MA.

Sartain, L., Stoelinga, S., \& Brown, E. (2011). Rethinking teacher evaluation in Chicago: Lessons learned from classroom observations, principal-teacher conferences, and district implementation. University of Chicago Consortium of Education. Retrieved from http://ccsr.uchicago.edu/publications/rethinking-teacherevaluation-chicago-lessons-learned-classroom-observations-principal

Sheppard, J.A. (2013). Perceptions of teachers and administrators regarding the teacher evaluation process (Doctoral dissertation). Retrieved from Electronic Thesis and 
Dissertations. htpps://digitalcommons.georgiasouthern.edu/etd/852

Schachter, R. (November). Brave new world of teacher evaluation. District Administration. Retrieved from https://eric.ed.gov/?id

Shute, V.J. (2008). Focus on formative feedback. Review of Educational Research, 78(1), 153-189.

Shulman, J.D. (1987). Those who understand: Knowledge growth in teaching. American Educational Research Association. 15(2) 4-14.

Spillane, J. (2012). Distributed leadership. San Francisco, California: Jossey-Bass.

Spillane, J., Reiser, B., \& Reimer, T (2002). Policy implementation and cognition: Reframing and refocusing implementation research. Review of Educational Research, 72(3) 387-431.

Statistics Solutions. (2013). Data analysis plan: Factorial ANOVA. Retrieved from http://www.statisticssolutions.com/academic-solutions/memberresources/member-profile/data-analysis-plan-templates/factorial-anova/

Stiggins, R., \& Bridgeford, N. (1985). The ecology of classroom assessment. Journal of Educational Measurement, 22, $271-286$.

Stiggins, R., \& Duke, D. (1988). The case for commitment to teacher growth: Research on teacher evaluation. New York, New York: State University of New York Press. 
Stiggins, R. J., \& Nickel, P. (1988). The teacher evaluation profile: A technical analysis. Journal of Personnel Evaluation in Education, 2,151-165.

Stumbo, C., \& McWalters, P. (2010). Measuring effectiveness: What will it take? Educational Leadership, 68(4) 10-15. Retrieved from http://www.ascd.org/publications/educationalleadership/dec10/vol68/num04/Measuring-Effectiveness@-What-Will-ItTaked.aspx

Tabachnick, B. G., \& Fidell, L. S. (2007). Using multivariate statistics. Boston: Pearson/Allyn \& Bacon.

Taylor, E. S., \& Tyler, J. H.. (2012). The effect of evaluation on teacher performance. The American Economic Review, 102(7), 3628-3651. Retrieved from http://www.jstor.org/stable/41724648

Towe, P.B. (2012). An investigation of the role of a teacher evaluation system and its influence on teacher practice and professional growth in four urban high schools. (Doctoral dissertation). Retrieved from ProQuest. (3520930).

Tschannen-Moran, M. (2007). The differential antecedents of self-efficacy beliefs of novice and experienced teachers.

U.S. Department of Education. (2016). Study of emerging teacher evaluation systems. Retrieved from https://www2.ed.gov/rschstat/eval/teaching/emerging-teacherevaluation/report.pdf 
U.S. Department of Education (1982). The Madeline Hunter model of mastery learning. Retrieved from https://www.doe.in.gov/sites/default/files/turnaround-principles/8steps-effective-lesson-plan-design-madeline-hunter.pdf

United States. Reform Support Network. (2013). Race to the top resources. United States Department of Education. Washington, D.C.

Valentine, J.W., \& Prater, M. (2011). Instructional, transformational, and managerial leadership and student achievement: High school principals make a difference. Sage Journals. 95, 5-30. https://doi.org/10.1177/0192636511404062

Vygotsky, L. (1978). Interaction between learning and development. Mind and society, 79-91. Retrieved from http://www.psy.cmu.edu/ siegler/vygotsky78.pdf

Waters, T., Marzano, R., \& McNulty, B. (2003). Balanced leadership: What 30 years of research tells us about the effect of leadership on student achievement. Balanced Leadership. Retrieved from https://www.mcrel.org/wp-

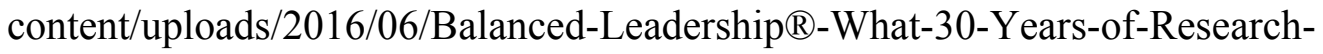
Tells-Us-about-the-Effect-of-Leadership-on-Student-Achievement.pdf.

Weems, D. M., \& Rogers, C. B. (2010). Are U.S. Teachers Making the Grade? A Proposed Framework for Teacher Evaluation and Professional Growth, Management in Education. Retrieved from http://eric.ed.gov/?id=EJ871676

Weisberg, D., Sexton, S., Mulhern, J., \& Keeling, D. (2009). The widget effect: Our national failure to acknowledge and act on differences in teacher effectiveness. 
The New Teacher Project. Retrieved from http://widgeteffect.org/downloads/TheWidgetEffect.pdf

Wright, P., Horn, S., \& Sanders, W. (1997). Teacher and classroom context effects on student achievement: Implications for teacher evaluation. Journal of Personnel Evaluation in Education, 11:57-67. Retrieved from http://www.growththroughlearningillinois.org/Portals/0/Documents/Teacher-andClassroom-Context-Effects.pdf 


\section{Appendix A \\ TEACHER PERCEPTION OF ADMINISTRATIVE SUPPORT FOR THE IMPLEMENTATION OF AN EVALUATION SYSTEM}

August 1, 2018

Dear teacher:

You are being invited to participate in a research study by answering questions in the attached survey about your perception of teacher evaluation and your perception of how your evaluating administrator supports you in the evaluation. This study is conducted by Dr. Immekus of the University of Louisville and Natalie Brown. There are no known risks for your participation in this research study. The information collected may not benefit you directly. The information learned in this study may be helpful to others. The information you provide will help administrators make informed decisions with support and professional development regarding teacher evaluation. Your completed survey will be stored at Qualtrics. The survey will take approximately fifteen minutes to complete. 
Individuals from the Department of Educational Leadership, Evaluation and Organizational Development, the Institutional Review Board (IRB), the Human Subjects Protection Program Office (HSPPO), and other regulatory agencies may inspect these records. In all other respects, however, the data will be held in confidence to the extent permitted by law. Should the data be published, your identity will not be disclosed.

Taking part in this study is voluntary. By answering survey questions you agree to take part in this research study. You do not have to answer any questions that make you uncomfortable (or prosecutable by law; if appropriate). You may choose not to take part at all. If you decide to be in this study you may stop taking part at any time. If you decide not to be in this study or if you stop taking part at any time, you will not lose any benefits for which you may qualify.

If you have any questions, concerns, or complaints about the research study, please contact: Dr. Jason Immekus at (502) 852 - 6475 or Natalie Brown at (502) 472 - 3020.

If you have any questions about your rights as a research subject, you may call the Human Subjects Protection Program Office at (502) 852-5188. You can discuss any questions about your rights as a research subject, in private, with a member of the Institutional Review Board (IRB). You may also call this number if you have other questions about the research, and you cannot reach the research staff, or want to talk to 
someone else. The IRB is an independent committee made up of people from the University community, staff of the institutions, as well as people from the community not connected with these institutions. The IRB has reviewed this research study.

If you have concerns or complaints about the research or research staff and you do not wish to give your name, you may call 1-877-852-1167. This is a 24-hour hot line answered by people who do not work at the University of Louisville.

\section{Click here to answer survey questions Click here to exit without answering survey questions}

Sincerely,

Jason Immekus, Ph.D. $\quad$ Natalie Brown 


\section{Appendix B}

\section{Teacher Evaluation Survey}

This form has been designed to allow you to describe your experience with teacher evaluation in some detail. Your responses will be combined with those of other teachers to yield a clearer picture of the key ingredients in an effective teacher evaluation experience. The goal of this research is to determine the impact of Danielson's Framework for Teaching. This questionnaire will take only a short time to complete. Please follow the instructions carefully and provide thoughtful responses.

\section{The Definition of Teacher Evaluation}

Teacher evaluation takes different forms in different school districts. For the purpose of this study, teacher evaluation procedures relate to the Danielson Framework that has been adopted by the state of Pennsylvania. It includes:

- Classroom observations

- Classroom walkthroughs

- Pre/post meetings with teacher evaluator

- Examination of lesson plans, materials or other artifacts

- Student achievement

When reference is made in this questionnaire to teacher evaluation, it should be understood to encompass any of these procedures that are followed in the evaluation program within your school district. 
Specific Instructions Please use the scales provided on the following pages to describe yourself and the nature of your most recent teacher evaluation experience in your school district.

Do this by:

- Considering each of the statements carefully.

- Studying the phrase to be used to describe each.

- Selecting the phrase that best represents your response.

Thank you for your participation.

\section{Demographic Information}

Including the current year, how many years have you been taught?
a. 0 - 3 years
b. 4 or more years

Based upon your knowledge and experience of the new teacher evaluation system, please respond to each of the statements below by selecting a number from 1 to 5 based on the following criteria:

5 - Strongly agree

4 - Agree 


\section{3 - Neither agree nor disagree}

\section{2 - Disagree}

\section{1 - Strongly disagree}

1. In general, the training workshops for the new teacher evaluation system thoroughly explained PGES, such that the explanation left me with no questions needed for clarification.

\section{5}

2. The trainers for the workshops thoroughly explained how PGES could help to enhance classroom teaching, such that the explanation left me with no questions needed for clarification.

\section{5}

3. I have a thorough understanding of how my district will use PGES for my observations, such that I have no questions about the process.

\section{5}


4. I have a thorough understanding of the performance levels in PGES (Unsatisfactory, Basic, Proficient, and Distinguished), such that I have no questions about the critical attributes that separate one teaching performance level from another.

\section{5}

5. The definition of effective teaching outlined by PGES thoroughly aligns with what I believe constitutes effective teaching.

\section{5}

6. Focusing on the teaching standards within PGES, in general, will lead to significant change in improving teaching performance.

\section{5}

7. The new teacher evaluation system (PGES) provides a completely accurate assessment of my performance.

\section{5}

8. The most important purpose of PGES is to enhance both teacher quality (accountability) and professional development (improvement/growth).

\section{5}


9. I almost always use the Framework to plan my instructional strategies prior to an observation.

12345

10. Component $3 \mathrm{~b}$ of PGES addresses instruction, specifically questioning and discussion techniques. Apart from observations, I often use the PGES Framework to self-assess my questioning and discussion strategies.

12345

11. Based upon my knowledge of the teaching performance levels (Unsatisfactory, Basic, Proficient, and Distinguished) within the PGES, I have made significant changes to the questioning strategies that I use in class.

12345

12. As part of the evaluation process, PGES will have a significant impact on improving my teaching performance.

12345

13. Feedback from my principal provides me mostly with specific comments related to the teaching standards identified in PGES

12345 
14. PGES provides mostly useful feedback on my performance.

\section{5}

15. The feedback from my principal during the post-conference meeting results in large changes resulting in improvements in my teaching practice.

12345

16. Apart from observations, I often use the Framework to self-assess my teaching

12345

17. PGES will have a significant impact on my professional growth.

123345

18. PGES has been very useful in improving my teaching.

\section{5}

19. The implementation of PGES will result in a very accurate method to measure teacher effectiveness.

12345 


\section{CURRICULUM VITA}

NAME: $\quad$ Natalie Redman Brown

ADDRESS: University of Louisville

$2301 \mathrm{~S} 3^{\text {rd }}$ Street

Louisville, KY 40292

DOB: $\quad$ Louisville, KY - September 22, 1975

EDUCATION

\& TRAINING: $\quad$ B.S., Communication Disorders

Eastern Kentucky University

1997

M.A.Ed., Teaching

Bellarmine University

2002

M.A.Ed., Educational Leadership

Bellarmine University

2011

Ed.D., Educational Leadership 
University of Louisville

2019

Selected Presentations

Brown, N., Corbin, B., Foster, J., Humphrey, A. (November, 2008). Tools for

Citizenship: Teaching Social Justice. Session presented at the annual meeting of the National Council of Teachers of English in San Antonio, TX.

Brown, N \& Punches-Guntsch, C. (September, 2016). Twelve angry teachers. Session presented at the Continuous Improvement Summit in Lexington, KY.

Brown, A. (September, 2017). Thirty day challenge to more effective teacher coaching. Session presented at the Continuous Improvement Summit in Lexington, KY.

Brown, N (February, 2018). Increasing the rigor in your classroom. Session presented at the Racial Equity Summit in Hopkinsville, KY. 